\title{
Erratum to: The Consequences of Tariff Reduction for Economic Activity and Inequality
}

\author{
Jorge Rojas-Vallejos ${ }^{1} \cdot$ Stephen J. Turnovsky ${ }^{1}$
}

Published online: 3 May 2015

(C) Springer Science+Business Media New York 2015

\section{Erratum to: Open Econ Rev (2015) \\ DOI 10.1007/s11079-015-9341-4}

This article was published with errors that were introduced during the publication process by the publisher who accepts full responsibility and apologizes for any inconvenience. The corrected version of the article appears below.

\begin{abstract}
The recent increase in trade liberalization has had substantial distributional consequences, although the direction of the relationship and the mechanism driving it has been open to debate. This paper analyzes the impact of tariff reductions on the dynamics of wealth and income inequality in a growing economy in which agents accumulate both physical capital and international bonds. Our study, which comprises a combination of formal analysis, supplemented with numerical simulations, suggests that in the long run the tariff reduction will be expansionary and be associated with both a permanent reduction in wealth inequality but an increase in income inequality, the magnitudes of which depend upon the speed with which the tariff reduction is implemented.
\end{abstract}

Keywords Tariffs $\cdot$ Economic activity $\cdot$ Wealth inequality $\cdot$ Income inequality

JEL Classification D31 $\cdot$ F13 $\cdot$ F41

The online version of the original article can be found at http://dx.doi.org/10.1007/s11079-015-9341-4.

Stephen J. Turnovsky

sturn@u.washington.edu

1 University of Washington, Seattle, WA 98195, USA 


\section{Introduction}

The last three decades have been a period of dramatic trade liberalization. This has primarily taken the form of a steady reduction in tariffs, accompanied by declining nontariff barriers, particularly by developing economies. These developments have been associated with an increase in inequality, as Goldberg and Pavcnik (2007) have documented in detail. As these authors have also discussed, due in large part to data limitations, empirical studies have been restricted almost entirely to wage inequality, focusing in particular on the rising wage differential associated with the skill premium. Clearly the consequences of trade liberalization for distributional issues are important. In this paper we address the effects of tariff reduction on both the level of activity and broader measures of income inequality in a neoclassical growth model of an open economy, in which heterogeneous agents accumulate physical capital as well as internationally traded bonds.

In a general setup in which aggregate quantities and their distributions across individuals are simultaneously determined, the analysis of their joint responses to a policy change such as a tariff reduction becomes intractable; see e.g., Sorger (2000). ${ }^{1}$ However, if one adopts the prevalent assumption throughout much of contemporary growth theory - specifically, the homogeneity of the underlying utility function - we can exploit the aggregation results due to Gorman (1953), thereby rendering the problem tractable. Under this assumption the macroeconomic equilibrium and distribution are determined sequentially. First, summing over individuals leads to a macroeconomic equilibrium in which aggregate quantities are determined independently of any distributional measures. This equilibrium structure has led Caselli and Ventura (2000) to characterize the resulting distribution as a "representative agent theory of distribution". But the tractability of the aggregation also depends upon the source of the agents' heterogeneity, which we take to be their initial endowments of physical capital and internationally traded bonds. In general, endowments are a key source of inequality, as Piketty (2011) and others have recently stressed, and in this international context, agents' initial endowments of the two assets seem the most relevant.

Having determined the macroeconomic equilibrium, we then derive the time path for relative wealth across agents, which we can then transform to a measure of wealth inequality. The dynamics of this measure depend on agents' relative labor supplies along the transitional path, and the consequences for the differential savings rates across the distribution of the heterogeneous agents. Finally, the evolution of income inequality is then determined by the interaction of the evolving wealth distribution with the changing share of income from wealth in total personal income.

Using this framework, we first derive a number of theoretical implications, linking the effects of tariffs on economic activity and inequality. It is straightforward to show that in the long run, a reduction in the tariff on the imported consumption good increases output, employment, capital, and wealth all in the same proportions, which depend upon the degree of openness of the economy in the commodities market. To the extent that the labor supply increases during the transition (in contrast to completely adjusting on impact) this will tend to reduce wealth inequality. In addition to this effect, income inequality is likely to increase due to a reduction in the aggregate consumption expenditure-wealth ratio, and the fact that the rich save relatively more (consume relatively less) than do the poor.

The interaction between aggregate quantities and their distributions across diverse agents is too complex for one to be able to advance beyond a few general but abstract statements. 
A key factor influencing the impact of tariffs on distribution concerns the speed with which the tariff reduction is implemented. This is important, since in practice there is substantial variation in the rate at which trade liberalizations have proceeded. ${ }^{2}$ We consider two scenarios. In the first, the tariff reduction is completed instantaneously, and we compare this to the alternative case where it is implemented gradually over time. While the time path affects only the transitional path of the aggregate variables, it has not only transitional but also permanent consequences for both wealth and income inequality. We find that a gradual reduction in the tariff rate intensifies the effects on wealth inequality, and reduces them on income inequality. This is due to its effect on expectations that people form regarding the future levels of tariffs and labor supply as the economy grows.

Because of the complexity of the model, it is necessary to conduct the dynamic analysis using numerical simulations. In calibrating the model, our intent is to set parameters so as to approximate a plausible initial equilibrium structure that will facilitate our understanding of the channels through which tariffs influence the equilibrium, rather than to replicate any specific economic episode. In particular, we assume an initial average tariff rate of $10 \%$, which approximates the average tariff rate in 1990 of the 45 countries in the Forbes (2000) sample. Starting from that point, we consider both the instantaneous and the gradual elimination of the tariff. In either case we find that in the long run, output and the aggregate capital stock increase by about 2-3\%, depending upon parameter values. In contrast, wealth inequality declines by under $1 \%$ if the tariff elimination is completed immediately, and by about $1.5-3 \%$ if implemented gradually. The comparable changes for income inequality are increases of $2-4 \%$ and $1-2 \%$, respectively.

Studies investigating the impact of tariffs on the aggregate economy date back to Mundell (1961). His analysis and its earliest extensions were static, employing some variant of the Mundell-Fleming model; see e.g., Boyer (1977), Chan (1978), Krugman (1982). The initial analysis of tariffs in a dynamic framework was Eichengreen (1981) who, using a currency substitution model, emphasized the intertemporal tradeoffs imposed by a tariff. Subsequent analyses by Sen and Turnovsky (1989), Gardner and Kimbrough (1989), Engel and Kletzer (1990), have analyzed tariffs in the context of a macrodynamic model based on intertemporal optimization. More recently, Fender and Yip (2000) and Hwang and Turnovsky (2013) analyze the effects of tariffs in the two-country "new open economy model" pioneered by Obstfeld and Rogoff $(1995,2000) .{ }^{3}$ All of this literature has assumed homogeneous agents (or cohorts), and hence none of these studies address the distributional consequences of tariff policy.

As already noted, over recent years, there has been a growing literature exploring the relationship between trade liberalization policies and inequality, yielding a range of results. For example, Savvides (1998) finds that among less developed countries, more open economies experienced increased income inequality during the late 1980s.

\footnotetext{
$2 \quad$ For example, we have examined the sample of 45 countries developed by Forbes (2000). There we see substantial variation in the speed with which countries reduced their tariffs over the period 1990-2010, for example. Generally we find that advanced economies tended to reduce them at a much slower rate than have developing countries (approximately $6 \%$ per annum versus $12 \%$ ).

3 Recognizing the diverse effects that tariffs may have on different parts of the economy, several papers have introduced tariffs into a multi-sector framework, thereby highlighting the role of the sectoral adjustments to the tariff; see Gavin (1991) and Turnovsky (1991). Other related references include Kimbrough (1982), Ostry (1991), and Yip (1995). One characteristic of the literature is that there is no consensus regarding the theoretical effects of tariffs on key macroeconomic variables, a finding that tends to be confirmed empirically by Ostry and Rose (1992).
} 
However, he found that trade policy has had no effect on income inequality in developed countries. At the same time, Harrison and Hanson (1999) find that trade reform has increased wage inequality for the case of Mexico, which contradicts the prediction by the Heckscher-Ohlin model. Likewise, Beyer et al. (1999) show that for the Chilean economy, openness widens the wage gap between unskilled and skilled workers, which in turn raises income inequality. Milanovic and Squire (2005) find that tariff reduction is associated with more wage inequality in poorer countries, while the reverse applies in richer countries. Bourguignon and Morrison (1990) analyze the relationship between income distribution and foreign trade in developing economies. They find that endowments in mineral resources, foreign trade distortions as well as secondary schooling are major determinants of differences in income inequality across developing countries. Furthermore, they show that protectionism seems to increase income inequality. Edwards (1997) presents a similar argument. Using data from Deininger and Squire (1997), he shows that the correlation between trade distortions and inequality is positive although not strongly statistically significant. His analysis seems to be robust to different measures of trade openness despite the data limitations. In contrast, Stewart and Berry (2000) claim that liberalization has increased income inequality within nations. They point out that countries' initial conditions and their policy setups play a significant role in how liberalization affects income inequality. They explain that if a country has a high-skilled labor force, then income inequality may be alleviated. However, as is the case of most middle-income countries, if there is concentration of a factor of production that is intensively used and the labor force is not high-skilled, then these countries show a sharp worsening in income distribution. Finally, in a recent paper Lim and McNelis (2014) use a panel to estimate the impact of trade-openness and other controllers on the income Gini coefficient. They find a non-monotonic behavior that depends upon the level of development of the country, analogous to that proposed in Kuznets' (1955) seminal contribution. With few exceptions the existing literature focuses on the political economy aspects of trade liberalization rather than the explicit role of tariff reduction, as is the focus here. ${ }^{4}$

The paper is organized as follows. Section 2 sets out the analytical framework, while Section 3 derives and characterizes the macroeconomic equilibrium. Section 4 characterizes the distributions of wealth, and income, and derives the main analytical results. Sections 5 and 6 illustrates these results with numerical simulations describing the effects of the elimination of tariffs. Section 7 concludes, while technical details are presented in Appendix A and B.

\section{Macroeconomic Model}

To begin, we develop a basic neoclassical model of an open economy that consumes two goods. One is produced domestically, while the other is imported and subject to a tariff. $^{5}$

\footnotetext{
Other recent studies include: Dreher and Gaston (2008), Bergh and Nilsson (2010), Jaumotte, Lall, and Papageorgiou (2013).

5 The model is a modification of Sen and Turnovsky (1989) to allow for heterogeneity among agents. It differs in one other respect from the earlier model in that agents' access to the world financial market is subject to frictions.
} 


\subsection{Firms}

The domestic good is produced by a single representative firm in accordance with the standard constant returns to scale neoclassical production function

$$
Y=F(K, L) \quad F_{K}>0, F_{L}>0, F_{K K}<0, F_{L L}<0, F_{K L}>0
$$

where $K, L$, and $Y$ denote the economy-wide average stock of capital, labor supply, and output, respectively. Capital depreciates at a constant rate, $\delta$, and factors are paid their respective marginal products so that the return to capital, $r$, and the wage rate, $w$, are determined by

$$
\begin{array}{cc}
r(K, L)=F_{K}(K, L)-\delta & r_{K}=F_{K K}<0, r_{L}=F_{K L}>0 \\
w(K, L)=F_{L}(K, L) & w_{K}=F_{L K}>0, w_{L}=F_{L L}<0
\end{array}
$$

\subsection{Consumers}

The economy is populated by a mass 1 of infinitely-lived individuals, indexed by $i$, who are identical in all respects except for their initial endowments of capital, $K_{i, 0}$, and of an internationally traded bond, $B_{i, 0}$. In this respect we should note that while there are many sources of heterogeneity, initial endowments are arguably among the most significant. Compelling evidence supporting this view is provided by Piketty (2011). Since we are interested in distribution and inequality we shall focus on individual $i$ 's relative holdings of capital and bonds, $k_{i}(t) \equiv K_{i}(t) / K(t), b_{i}(t) \equiv B_{i}(t) / B(t)$, where $B(t)$ denotes the economy-wide average stock of bonds. Initial relative endowments, $k_{i, 0}$, $b_{i, 0}$ have mean 1 and relative standard deviations, $\sigma_{k, 0}, \sigma_{b, 0}$ across agents. ${ }^{6}$ Each agent is also endowed with one unit of time that he can allocate to labor, $L_{i}$ or enjoy as leisure, $l_{i}$, so that $l_{i}(t)+L_{i}(t)=1$. With a continuum of agents, the economy-wide average supply of labor is $L=\int_{0}^{1} L_{i} d i$ and other aggregates are defined analogously.

Each individual $i$ has lifetime utility that depends upon the following isoelastic function of the domestic consumption good, $x_{i}$, the imported consumption good, $y_{i}$, and leisure

$$
U_{i}=\int_{0}^{\infty} \frac{1}{\gamma}\left(x_{i}(t)^{\theta} y_{i}(t)^{1-\theta} l_{i}(t)^{\eta}\right)^{\gamma} e^{-\beta t} d t \quad 0 \leq \theta \leq 1,0<\eta,-\infty<\gamma \leq 1, \theta \gamma<1, \eta \gamma<1
$$

where $1 /(1-\gamma)$ is the agent's intertemporal elasticity of substitution, $\theta$ measures the relative importance of domestic vs. imported consumption, and therefore parameterizes the degree of openness from the consumption standpoint. The exponent, $\eta$, parameterizes the relative importance of leisure and $\beta$ is the subjective discount rate. The remaining restrictions in (3a) ensure concavity of the utility function in the two consumption goods and leisure.

We assume that the agent chooses his rates of consumption, $x_{i}(t), y_{i}(t)$, and rates of accumulation of capital, $K_{i}(t)$, and traded bonds, $B_{i}(t)$, so as to maximize (3a), subject to his instantaneous budget constraint, expressed in terms of units of domestic output as numeraire:

\footnotetext{
These initial endowments can be perfectly arbitrary and therefore consistent with any required nonnegativity constraints. As will become apparent in the course of the analysis, the form of the distribution of the initial endowments will be reflected in the evolving distributions of wealth and income.
} 


$$
\begin{aligned}
s(t) \dot{B}_{i}(t)+\dot{K}_{i}(t)= & w(K, L) L_{i}(t)+r(K, L) K_{i}(t) \\
& +i\left(\frac{s B}{K}\right) s(t) B_{i}(t)-x_{i}(t)-(1+\tau(t)) s(t) y_{i}(t)+T_{i}(t)
\end{aligned}
$$

given his initial endowments of capital and bonds. Equation ( $3 b)$ asserts that the agent earns income from supplying labor, renting capital, the interest earned on his holdings of traded bonds, and from lump-sum transfers from the government, $T_{i}$. The excess of these income sources over his consumption expenditures (inclusive of the tariff on the imported good) is accumulated in the form of domestic capital goods and foreign bonds, where $s(t)$ denotes the relative price of the foreign good in terms of the domestic good, and $\tau(t)$ denotes the rate of the tariff at time $t$.

The constraint ( $3 \mathrm{~b}$ ) pertains to a lender or borrower according to whether $B_{i}>0$ or $D_{i} \equiv-B_{i}>0$, and the equilibrium outcome depends upon the relative magnitudes of the rate of time preference and the given world interest rate, $i^{*}$. In either case a key element of the model is that while the economy has access to the international capital market, it faces frictions, expressed by the relationships

$$
\begin{gathered}
i\left(\frac{s D}{K}\right)=i^{*}+\omega\left(\frac{s D}{K}\right) \omega(0)=0, \omega^{\prime}>0, \omega^{\prime \prime}>0 \\
i\left(\frac{s B}{K}\right)=i^{*}-\omega\left(\frac{s B}{K}\right) \omega(0)=0, \omega^{\prime}>0, \omega^{\prime \prime}>0
\end{gathered}
$$

Equation (4a), specifies the familiar convex increasing borrowing costs facing a debtor country. ${ }^{7}$ According to this relationship the borrowing premium is assumed to be an increasing ratio of the country's stock of foreign bonds to capital, which the individual agent, being atomistic, assumes that he cannot influence. Equation (4b) expresses a parallel relationship in the case of a creditor nation. In either case, normalizing by the stock of capital means that larger economies are less constrained by the financial friction implicit in $(4 \mathrm{a}, 4 \mathrm{~b})$. The shape of the function $\omega($.$) reflects the 'openness' of$ the economy with respect to the financial market.

Performing the optimization yields the following first order optimality conditions:

$$
\begin{gathered}
\theta\left(x_{i}\right)^{\gamma \theta-1}\left(y_{i}\right)^{\gamma(1-\theta)}\left(l_{i}\right)^{\gamma \eta}=v_{i} \\
(1-\theta)\left(x_{i}\right)^{\gamma \theta}\left(y_{i}\right)^{\gamma(1-\theta)-1}\left(l_{i}\right)^{\gamma \eta}=s(1+\tau) v_{i} \\
\eta\left(x_{i}\right)^{\gamma \theta}\left(y_{i}\right)^{\gamma(1-\theta)}\left(l_{i}\right)^{\gamma \eta-1}=w v_{i} \\
r(K, L)=\beta-\frac{\dot{v}_{i}}{v_{i}} \\
r(K, L)=i\left(\frac{s B}{K}\right)+\frac{\dot{s}}{s}
\end{gathered}
$$

\footnotetext{
Many variants of this relationship can be found. A commonly adopted alternative in the case of debtor countries is to specify the borrowing premium in terms of the ratio of debt to output, as a measure of the country's debt servicing ability. This has similar properties to the chosen specification.
} 
where $v_{i}$ is agent $i$ 's shadow value of wealth, associated with foreign assets. Equations (5a)-(5c) are standard static efficiency conditions, equating the marginal benefits of consumption and leisure to their respective marginal costs, while (5d) and (5e) are conventional arbitrage conditions equating the rates of return on investment, lending/ borrowing, and the rate of return on consumption. In addition, the following transversality conditions hold

$$
\lim _{t \rightarrow \infty} v_{i} K_{i} e^{-\beta t}=0 ; \lim _{t \rightarrow \infty} v_{i} s(t) B_{i} e^{-\beta t}=0
$$

Dividing (5b) and (5c) by (5a) yields

$$
\begin{gathered}
\theta(1+\tau(t)) s(t) y_{i}(t)=(1-\theta) x_{i}(t) \\
\theta w(t) l_{i}(t)=\eta x_{i}(t)
\end{gathered}
$$

Defining agent $i$ 's total consumption expenditure, inclusive of the tariff, by $C_{i}=$ $x_{i}+(1+\tau(t)) s y_{i}$, we may write

$$
\begin{gathered}
x_{i}(t)=\theta C_{i}(t) \\
(1+\tau(t)) s(t) y_{i}(t)=(1-\theta) C_{i}(t) \\
w(t) l_{i}(t)=\eta C_{i}(t)
\end{gathered}
$$

Thus each agent consumes the two consumption goods and leisure in the same proportion.

In practice, programs of trade liberalization, and specifically tariff reductions, are likely to involve extensive negotiations and therefore may well be implemented gradually over an extended period of time. To allow for this we assume that the tariff rate is adjusted gradually from its initial rate, $\tau_{0}$, to its post liberalization rate, $\widetilde{\tau}$, in accordance with the known path

$$
\tau(t)=\widetilde{\tau}+\left(\tau_{0}-\widetilde{\tau}\right) e^{-\lambda t}
$$

The parameter, $\lambda$, thus defines the speed with which the tariff change occurs and hence the time path it follows. The conventional assumption where the tariff is fully adjusted instantaneously is obtained by letting $\lambda \rightarrow \infty$ in (8). ${ }^{8}$ But the more general specification introduced in (8) is important. This is because, as we will demonstrate in our numerical simulations, there is a sharp contrast between how $\lambda$ affects the dynamics of aggregate quantities and of distributions across agents. As one would expect, the time path of tariffs affects the transitional path of the aggregate economy and not the aggregate

\footnotetext{
$8 \quad$ The assumption that the change in the tariff rate occurs at a constant proportionate rate, and is completed only asymptotically, is made purely for analytical convenience. It is straightforward to generalize (8) to the case where the new level of the tariff is reached in finite time, $T$. The analysis could also be modified to allow for the increase in the tariff to follow a more general time path, and the same general qualitative conclusions would emerge.
} 
steady state. But in contrast, it influences both the time paths and the steady-state levels of both wealth and income inequality, thereby having permanent distributional effects.

Taking the time derivatives of (7a) - (7c), and combining with (5d) and (5e), we obtain

$$
\frac{\dot{x_{i}}}{x_{i}}=\frac{\dot{C_{i}}}{C_{i}}=\frac{1}{1-\gamma(1+\eta)}\left[[1-\gamma(1-\theta)] r(K, L)+\gamma(1-\theta) i\left(\frac{s B}{K}\right)-\beta-\eta \gamma \frac{\dot{w}}{w}-\gamma(1-\theta)\left(\frac{\dot{\tau}}{1+\tau}\right)\right]
$$

$$
\frac{\dot{y_{i}}}{y_{i}}=\frac{1}{1-\gamma(1+\eta)}\left[\gamma(\theta+\eta) r(K, L)+[1-\gamma(\theta+\eta)] i\left(\frac{s B}{K}\right)-\beta-\eta \gamma \frac{\dot{w}}{w}-\left[1-\gamma(\theta+\eta)\left(\frac{\dot{\tau}}{1+\tau}\right)\right]\right.
$$

$$
\frac{\dot{l}_{i}}{l_{i}}=\frac{1}{1-\gamma(1+\eta)}\left[[1-\gamma(1-\theta)] r(K, L)+\gamma(1-\theta) i\left(\frac{s B}{K}\right)-\beta-(1-\gamma) \frac{\dot{w}}{w}-\gamma(1-\theta)\left(\frac{\dot{\tau}}{1+\tau}\right)\right]
$$

With the right hand side of Eqs. (9) being common to all agents, these equations imply that each individual, $i$, will choose the same growth rate for the two consumption goods and for leisure, in which case these will also equal the corresponding economy-wide growth rate. Thus,

$$
\frac{\dot{x}}{x}=\frac{\dot{x_{i}}}{x_{i}}=\frac{\dot{C_{i}}}{C_{i}}=\frac{\dot{C}}{C} ; \quad \frac{\dot{y}}{y}=\frac{\dot{y_{i}}}{y_{i}} ; \quad \frac{\dot{l}}{l}=\frac{\dot{l}_{i}}{l_{i}} \text { for all } i
$$

In particular, we may write $C_{i}=\varphi_{i} C$, where $\int_{0}^{1} \varphi_{i} d i=1$, and $\varphi_{i}$, which defines agent $i$ 's relative consumption, is constant over time for each $i$, and is yet to be determined; see footnote 14 below.

\subsection{The Government}

To isolate the impact of the tariff, the domestic government is assigned a very minor role, simply levying the tariff on the imported consumption good and then rebating the revenues to consumers. ${ }^{10}$ It issues no debt, nor conducts any other expenditures, maintaining a balanced budget in accordance with

$$
T(t)=\tau(t) s(t) y(t)
$$

We assume that the tariff revenues are rebated uniformly across the agents so that $T_{i}(t)=$ $T(t)$, for each $i$.

The reason for this is the homogeneity of the utility function (3) which causes individuals to maintain fixed relative consumption over time. This introduces a "zero root" into the dynamics of the distributional measures, as a result of which their equilibrium values become path dependent; see Atolia et al. (2012) where this issue is discussed in detail in the context of a Ramsey model.

Another assumption that would also isolate the role of the tariff would be to assume that the tariff revenues are allocated to government expenditure which has no impact on private behavior. Alternatively, if we were to assume that the tariff revenues are spent on some activity that enhances private productivity say, we would have the difficulty of disentangling the effect of the tariff from that the productive effect of the expenditure. 


\section{Macroeconomic Equilibrium}

Because of the linearity of the optimality conditions in quantities pertaining to the individuals, aggregation is straightforward. Thus, summing (7) over all individuals, we can express the equilibrium aggregate economy-wide consumption levels, $x(t), y(t), C(t)$ in terms of aggregate quantities of capital and labor, the relative price, $s(t)$, and the prevailing tariff rate, $\tau(t)$

$$
\begin{gathered}
x(t)=\frac{\theta}{\eta} F_{L}(K, L)(1-L) \\
y(t)=\frac{(1-\theta)}{\eta} \frac{F_{L}(K, L)(1-L)}{s(t)(1+\tau(t))} \\
C(t)=\frac{1}{\eta} F_{L}(K, L)(1-L)
\end{gathered}
$$

To determine the macrodynamic equilibrium, we first assume domestic goods market clearance:

$$
F(K, L)=x+Z(s)+I
$$

where $Z(s)$ denotes the exports of the domestic good and we assume that $Z^{\prime}(s)>0$, and $I=\dot{K}+\delta K$ is the aggregate gross investment in the domestic economy. ${ }^{11}$ Using (11a), (12) can be expressed in the form of the capital accumulation equation

$$
\dot{K}(t)=F(K, L)-\frac{\theta}{\eta} F_{L}(K, L)(1-L)-Z(s)-\delta K
$$

Next, aggregating over the individual budget constraints (3b), noting the linear homogeneity of the production function, using the optimality conditions, (11), and the government budget constraint, (10), yields the current account relationship

$$
\dot{B}(t)=\frac{Z(s)}{s}-\frac{(1-\theta)}{(1+\tau(t)) s \eta} F_{L}(K, L)(1-L)+i\left(\frac{s B}{K}\right) B
$$

This equation asserts that the aggregate rate of accumulation of traded bonds equals the balance of trade, given by the first two terms, plus the earnings on the country's net holdings of foreign bonds.

Recalling the return to capital, defined in (2a), the arbitrage condition (5e) implies

$$
\frac{\dot{s}(t)}{s(t)}=F_{K}(K, L)-\delta-i\left(\frac{s B}{K}\right)
$$

\footnotetext{
In general, $Z($.) is determined abroad by factors that the small country being considered here takes as given. Since we are not trying to explain behavior in the rest of the world, we simply postulate that the quantity of exports increases as the domestic real exchange rate depreciates (i.e. as $s$ increases).
} 
To obtain the remaining dynamic equation, determining the evolution of the aggregate labor supply, we aggregate $(9 \mathrm{c})$ over the agents and combine with the relationship $\dot{w}$ / $w=\left[F_{L K} \dot{K}+F_{L L} \dot{L}\right] / F_{L}$ and the adjustment of tariffs (8). This is straightforward but tedious, and omitting details, leads to the relationship

$$
\begin{aligned}
\dot{L}(t)= & \frac{(1-L) F_{L}}{(1-\gamma) F_{L L}(1-L)-F_{L}[1-\gamma(1+\eta)]}\left\{[1-\gamma(1-\theta)]\left(F_{K}(K, L)-\delta\right)+\gamma(1-\theta) i\left(\frac{s B}{K}\right)-\beta\right. \\
& \left.+\gamma(1-\theta) \lambda\left(\frac{\tau(t)-\widetilde{\tau}}{1+\tau(t)}\right)-(1-\gamma) \frac{F_{L K}}{F_{L}}\left[F(K, L)-\frac{\theta}{\eta} F_{L}(K, L)(1-L)-Z(s)-\delta K\right]\right\}
\end{aligned}
$$

Equations (13a)-(13d) summarize the macrodynamic equilibrium in terms of the evolution of $K(t), B(t), s(t)$, and $L(t)$. This describes the "internally" generated aggregate dynamics and is conditional on the evolution of tariffs, $\tau(t)$. To complete the macrodynamic equilibrium we require the externally specified dynamics of tariff adjustment, which are obtained by taking the time derivative of (8)

$$
\dot{\tau}(t)=\lambda[\widetilde{\tau}-\tau(t)]
$$

Once (13a)-(13e) are determined, the corresponding aggregate consumption levels of the domestic and imported consumption goods can be derived from (11a)-(11c). The key observation is that the aggregate equilibrium is independent of any distributional aspects. This is a consequence of: (i) the homogeneity of the utility function, (ii) the perfect factor markets, and (iii) the assumption that all individuals have equal access to the international financial markets. Under these assumptions, we can aggregate over the agents, as Gorman (1953) originally noted, giving rise to the "representative agent theory of distribution" as Caselli and Ventura (2000) have stressed more recently.

\subsection{Steady State}

The steady-state equilibrium to this open economy is attained by setting $\dot{K}=\dot{B}=\dot{S}=\dot{L}=\dot{\tau}=0$ and is conveniently summarized by the following relationships:

$$
\begin{gathered}
F(\widetilde{K}, \widetilde{L})-\theta \widetilde{C}-Z(\widetilde{s})-\delta \widetilde{K}=0 \\
Z(\widetilde{s})-\frac{(1-\theta)}{(1+\widetilde{\tau})} \widetilde{C}+i\left(\frac{\widetilde{s} \widetilde{B}}{\widetilde{K}}\right) \widetilde{B} \widetilde{s}=0 \\
F_{K}(\widetilde{K}, \widetilde{L})-\delta=i\left(\frac{\widetilde{s} \widetilde{K}}{\widetilde{K}}\right) \\
F_{K}(\widetilde{K}, \widetilde{L})-\delta=\beta \\
\widetilde{C}=\frac{1}{\eta} F_{L}(\widetilde{K}, \widetilde{L})(1-\widetilde{L})
\end{gathered}
$$


Combining (14c), (14d) with (4), we see that $\omega(\widetilde{s} \widetilde{B} / \widetilde{K})_{*}=i^{*}-\beta$, so that in steady state, the country is a creditor (debtor) according to whether $i>(<) \beta$.

With the equilibrium capital-labor ratio being determined by the modified goldenrule condition, (14d), we immediately see that the steady-state capital-labor ratio is independent of the tariff. ${ }^{12}$ Equation (14c) then implies that the same is true for the ratio of the value of traded bonds, expressed in terms of domestic output, $\widetilde{B^{\prime}} \equiv \widetilde{s} \widetilde{B}$ to capital.

From (14) we derive:

$$
\begin{gathered}
d \widehat{\widetilde{Y}}=d \widehat{\widetilde{L}}=d \widehat{\widetilde{K}}=d \widehat{\widetilde{B}}^{\prime}=d \widehat{\widetilde{V}}=-\frac{\widetilde{C}(1-\theta)}{1+\widetilde{\tau}}\left(\frac{1}{\beta \widetilde{V}+F_{L} \widetilde{L}\left[1+\frac{(1+\theta \widetilde{\tau})}{(1+\widetilde{\tau}) \eta}\right)}\right) \frac{d \widetilde{\tau}}{1+\widetilde{\tau}}=-\Theta \frac{d \widetilde{\tau}}{1+\widetilde{\tau}}<0 \\
d \widehat{\widetilde{C}}=\frac{\widetilde{L}}{1-\widetilde{L}} \Theta \frac{d \widetilde{\tau}}{1+\widetilde{\tau}}>0 \\
d \widehat{\widetilde{C}}-d \widehat{\widetilde{V}}=\Theta \frac{d \widetilde{\tau}}{1+\widetilde{\tau}}>0 \\
d \widetilde{s}=-\frac{1}{Z^{\prime}}\left[\beta \widetilde{K}+F_{L} \widetilde{L}+\frac{\widetilde{C} \widetilde{L}}{1-\widetilde{L}}\right] \Theta \frac{d \widetilde{\tau}}{1+\widetilde{\tau}}<0
\end{gathered}
$$

Thus, long-run capital, labor, output, domestically valued bonds, wealth (expressed in domestic units, $\widetilde{K}+\widetilde{s} \widetilde{B}$ ) all decline in the same proportion to an increase in the tariff. At the same time, an increase in the tariff in general raises overall long-run consumption expenditures inclusive of the tariff, while lowering the relative price of imported goods.

\subsection{Transitional Dynamics}

In Section 6 below we shall analyze the local dynamics following a decrease in the tariff rate, by linearizing Eqs. (13) about their steady state (14). The formal structure of this system is set out in the Appendix, where the unique stable adjustment path is characterized. There it is strongly suggested that the system exhibits saddlepoint behavior in the neighborhood of the steady state. ${ }^{13}$ Given the specified trajectory for tariffs that may or may not evolve sluggishly, depending upon $\lambda$, describes a two-

This is a consequence of the assumption that the tariff is levied only on consumption goods. This characteristic would no longer hold if imports also include investment goods, which were subject to tariffs.

13 It is possible by examining the characteristic equation of the dynamic system to derive the formal condition for there to be two positive and two negative eigenvalues. However, such exercises are not only very tedious, and in the end not very illuminating, and we find it much more useful to rely on our simulation results to establish the plausibility of this desired root configuration. 
dimensional stable manifold, along which both capital and foreign bonds evolve gradually, while the relative price and employment may respond instantaneously to new information as it comes available.

\section{Wealth and Income Inequality}

We now analyze the consequences of tariff liberalization for the evolution of wealth and income inequality.

\subsection{Wealth Inequality}

To abstract from any direct, but arbitrary, discretionary distributional effects arising from lump-sum transfers, we assume that tariff revenues are rebated uniformly across the agents, namely $T_{i}(t)=T(t)$, for all $i$. The wealth of agent $i$, measured in terms of domestic output is defined by

$$
V_{i}=K_{i}+s B_{i}
$$

Taking the time derivative of this relation, using the individual's budget constraint, (3b), the arbitrage condition (5e), and the distributional assumption $T_{i}(t)=T(t)$, the rate of wealth accumulation for agent $i$ is given by

$$
\dot{V}_{i}(t)=r(K, L) V_{i}(t)-C_{i}(t)+w(K, L) L_{i}+T
$$

Recalling (7c) this can be written as

$$
\dot{V}_{i}(t)=r(K, L) V_{i}(t)+w(K, L)+T-(1+\eta) C_{i}(t)
$$

and aggregating over all agents $i$ yields

$$
\dot{V}(t)=r(K, L) V(t)+w(K, L)+T-(1+\eta) C(t)
$$

Next, we define individual $i$ 's share of aggregate wealth to be $v_{i} \equiv V_{i} / V$. Taking the time derivative of $v_{i}$ and combining with (16) and (16'), together with $C_{i}=\varphi_{i} C$, we obtain

$$
\dot{v_{i}}=\frac{1}{V}\left\{[C-T-w(K, L)]\left(v_{i}-1\right)+(1+\eta)\left(1-\varphi_{i}\right) C\right\}
$$

Equation (17) indicates how the evolution of an individual agent's relative wealth depends upon the evolution of aggregate gross consumption expenditure, the real wage rate, as well as his own specific endowments as reflected in $v_{i}$ and $\varphi_{i}$.

Before solving for $v_{i}(t)$ we consider some of the steady-state relationships between consumption and wealth. First, considering (16') at steady state and using (11c), we see that

$$
\widetilde{C}=\beta \widetilde{V}+\widetilde{T}+\widetilde{w}(\widetilde{K}, \widetilde{L}) \widetilde{L}
$$


so that aggregate steady-state consumption equals the income from wealth, plus wage income, plus the tariff revenue. Using (18) and (7c), the steady state of (17) can be written in the equivalent forms ${ }^{14}$ :

$$
\begin{gathered}
\widetilde{C}_{i}-\widetilde{C}=\frac{\beta}{1+\eta} \widetilde{V}\left(\widetilde{v}_{i}-1\right)=\frac{\beta}{1+\eta}\left(\widetilde{V}_{i}-\widetilde{V}\right) \\
\widetilde{L}_{i}-\widetilde{L}=-\frac{\beta \widetilde{V}}{\widetilde{w}}\left(\frac{\eta}{1+\eta}\right)\left(\widetilde{v}_{i}-1\right)=-\frac{\beta}{\widetilde{w}}\left(\frac{\eta}{1+\eta}\right)\left(\widetilde{V}_{i}-\widetilde{V}\right)
\end{gathered}
$$

From (19a) we see that if agent $i$ 's wealth places him above the average, his long-run marginal propensity to consume (inclusive of the tariff) out of his above-average component of his wealth equals $\beta /(1+\eta)$. Moreover, since (18) implies $\widetilde{C}>\beta \widetilde{V}$, it follows that the average long-run propensity to consume out of wealth exceeds $\beta$, implying that wealthier agents save proportionately more and consume proportionately less. From (19b) we see that, with a uniform wage, in the long run relatively wealthy people work less and enjoy more leisure.

To analyze the evolution of relative wealth, we linearize (17) around the steady state. In doing so, we take account of the fact that $L(t)$ evolves in accordance with $(13 \mathrm{~d}), w(K$, $L)$ reflects the accumulation of capital, (13a), and $T=\tau(1-\theta) C /(1+\tau)$. Omitting details, the linearized equation becomes (see Appendix A.2) ${ }^{15}$ :

$$
\dot{v}_{i}(t)=\beta\left(v_{i}(t)-\widetilde{v}_{i}\right)-\frac{\left(\widetilde{v}_{i}-1\right)}{\widetilde{V}}\left[\left(\frac{\widetilde{F_{L}}}{1-\widetilde{L}}\right)(L(t)-\widetilde{L})+\widetilde{C} \frac{(1-\theta)}{(1+\widetilde{\tau})^{2}}(\tau-\widetilde{\tau})\right]
$$

The key observation about (20) is that the coefficient of $v_{i}(t)>0$. Thus in order for the long-run distribution of wealth to be non-degenerate, each agent's relative wealth must remain bounded. To achieve this requires that the solution for $v_{i}(t)$ is given by the forward-looking solution ${ }^{16}$ :

$v_{i}(t)-1=\left(\widetilde{v}_{i}-1\right)\left[1+\frac{1}{\widetilde{V}}\left(\frac{\widetilde{F_{L}}}{1-\widetilde{L}}\right) \int_{t}^{\infty}(L(u)-\widetilde{L}) e^{-\beta(u-t)} d u+\frac{1}{\widetilde{V}}\left(\frac{\widetilde{s} \widetilde{y}}{1+\widetilde{\tau}}\right) \int_{t}^{\infty}(\tau(u)-\widetilde{\tau}) e^{-\beta(u-t)} d u\right]$

where in writing (21) use is made of (11b) and (11c). Setting $t=0$ in (21) enables us to determine the steady-state relative wealth, $\widetilde{v}_{i}$ in terms of the relative wealth at time 0 , namely

$$
\left(\widetilde{v}_{i}-1\right)=\left(v_{i}(0)-1\right)\left[1+\frac{1}{\widetilde{V}}\left(\frac{\widetilde{F}_{L}}{1-\widetilde{L}}\right) \int_{0}^{\infty}(L(u)-\widetilde{L}) e^{-\beta(u-t)} d u+\frac{1}{\widetilde{V}}\left(\frac{\widetilde{s} \tilde{y}}{1+\widetilde{\tau}}\right) \int_{0}^{\infty}(\tau(u)-\widetilde{\tau}) e^{-\beta(u-t)} d u\right]^{-1}
$$

and letting $t \rightarrow \infty$ in (21) we see that $\lim _{t \rightarrow \infty} v_{i}(t)=\widetilde{v}_{i}$.

\footnotetext{
$14 \quad$ This implies $\varphi_{i}-1=(\beta \widetilde{V} / \widetilde{C})(1+\eta)^{-1}\left(\widetilde{v}_{i}-1\right)$ and since $\beta \widetilde{V} / \widetilde{C}<1$ this implies consumption inequality, which remains constant over time is less than long-run wealth inequality.

15 The procedure we are following is developed in greater detail in Turnovsky and García-Peñalosa (2008).

16 Otherwise $v_{i} \rightarrow \pm \infty$, depending upon the agent's initial endowment.
} 
In general, the initial jumps in $s(0)$ and $L(0)$ following a structural change, including a tariff decrease, will cause an initial jump in $v_{i}(0)$ from its previous stationary level. For the simulations we perform this turns out to be extremely small, and it will be exactly zero if initially all agents hold the same portfolio shares, as we shall henceforth assume. 17 Because of the linearity of (21) and (21') across agents, these equations, which describe a specific agent's relative asset position, can be directly transformed into a corresponding relationship describing the relative distribution of wealth across agents, which therefore serves as a convenient measure of wealth inequality:

$$
\begin{gathered}
\sigma_{v}(t)=\chi(t) \widetilde{\sigma}_{v} \\
\sigma_{v, 0}=\chi(0) \widetilde{\sigma}_{v}
\end{gathered}
$$

where for notational convenience

$$
\chi(t) \equiv\left[1+\frac{1}{\widetilde{V}}\left(\frac{\widetilde{F}_{L}}{1-\widetilde{L}}\right) \int_{t}^{\infty}(L(u)-\widetilde{L}) e^{-\beta(u-t)} d u+\frac{1}{\widetilde{V}}\left(\frac{\widetilde{s} \widetilde{y}}{1+\widetilde{\tau}}\right) \int_{t}^{\infty}(\tau(u)-\widetilde{\tau}) e^{-\beta(u-t)} d u\right]
$$

Thus given $\sigma_{v, 0},(22)$ determines the entire time path of $\sigma_{v}(t)$.

Written in this way we can see that the dynamics of relative wealth, and therefore its distribution across agents, is driven by the evolution of two factors along the transitional path. The first is labor supply and its impact on the wage rate; the second is the time path over which tariffs are reduced and its impact on import costs. If (i) labor jumps immediately to its new steady state, and (ii) tariffs are fully adjusted immediately $[L(u)=\widetilde{L}, \tau(u)=\widetilde{\tau}]$, then $\chi(t)=1$ for all $t \geq 0$, and wealth inequality remains unchanged at its initial pre-shock level. Otherwise, to the extent that labor supply increases during the transition, it reduces the real wage and raises the return to capital. This tends to favor wealthier agents, who own more of the capital, causing $\chi(t)$ to decline and leading to a permanent increase in wealth inequality. In contrast, to the extent that the tariff is reduced gradually, this tends to reduce wealth inequality. This is because with only gradual tariff reduction, its expansionary effects occur only gradually, leading to a decline in labor supply and an increase in leisure. Since wealthier agents enjoy proportionately more leisure, they reduce their labor supply by proportionately more [see (19b)], causing them to accumulate wealth at a relatively slower rate, thereby reducing wealth inequality. We may summarize this in:

Proposition 1: To the extent that labor supply is increasing (decreasing) during the transition it will lead to a permanent increase (decrease) in wealth inequality. To the extent that the tariff is reduced (increased) gradually it will lead to a permanent decrease (increase) in wealth inequality.

To compute $v_{i}(t)-1$ and $\sigma_{v}(t)$ along the transitional path we substitute $L(t)-\widetilde{L}$ from (A.2d) and $\tau(t)-\widetilde{\tau}$ from (8) into (21) and (22). Omitting details, the solution can now be expressed as

$$
v_{i}(t)-1=\chi(t)\left(\widetilde{v}_{i}-1\right)
$$

$\overline{17}$ That is we assume $K_{i, 0} / K_{j, 0}=B_{i, 0} / B_{j, 0}$ for each $i, j$. 
where evaluating (22c)

$$
\begin{gathered}
\chi(t)=1+\frac{\Omega_{1}}{\mu_{1}-\beta} e^{\mu_{1} t}+\frac{\Omega_{2}}{\mu_{2}-\beta} e^{\mu_{2} t}-\frac{\Omega_{3}}{\lambda+\beta} e^{-\lambda t} \quad\left(22 \mathrm{c}^{\prime}\right) \\
\Omega_{1}=-\frac{A_{1}}{\widetilde{V}}\left(\frac{F_{L}}{1-\widetilde{L}}\right) \kappa_{41}, \quad \Omega_{2}=-\frac{A_{2}}{\widetilde{V}}\left(\frac{F_{L}}{1-\widetilde{L}}\right) \kappa_{42}, \Omega_{3}=-\left[\frac{\widetilde{s} \widetilde{y}}{1+\widetilde{\tau}}+\left(\frac{F_{L}}{1-\widetilde{L}}\right) \frac{\pi_{4}}{\widetilde{V}}\right]\left(\tau_{0}-\widetilde{\tau}\right)
\end{gathered}
$$

\subsection{Income Inequality}

The income measure we consider is taken to include labor income, interest earned on wealth, and the transfers received from the tariff revenues. Using the arbitrage condition, agent $i$ 's income is

$$
Q_{i}(t)=r(t) V_{i}(t)+w(t) L_{i}(t)+T(t)
$$

with aggregate income being:

$$
Q(t)=r(t) V(t)+w(t) L(t)+T(t)
$$

so that the agent's relative income, $q_{i}(t)=Q_{i}(t) / Q(t)$, is

$$
q_{i}(t)-1=\frac{1}{r(t) V(t)+w(t) L(t)+T(t)}\left[r(t) V(t)\left(v_{i}(t)-1\right)+w(t)\left(L_{i}(t)-L(t)\right)\right]
$$

From the relationship (7c) and its aggregate, together with the relationship $C_{i}=\varphi_{i} C$, yields $w\left(L_{i}-L\right)=-\eta C\left(\varphi_{i}-1\right)$, where the constant $\varphi_{i}$ is given from the steady-state relationship (A.7) in the Appendix; see also footnote 13. Using this relationship, together with (23), enables us to relate agent $i$ 's relative income to his relative wealth by

$$
q_{i}(t)-1=\varepsilon(t)\left[1-\left(\frac{\eta}{1+\eta}\right)\left(\frac{C(t)}{\widetilde{C}}\right)\left(\frac{\beta \widetilde{V}}{r(t) V(t)}\right) \frac{1}{\chi(t)}\right]\left(v_{i}(t)-1\right)
$$

where $\varepsilon(t) \equiv r(t) V(t) /[r(t) V(t)+w(t) L(t)+T(t)]$ denotes the share of income from wealth in total personal income. Because of the linearity of (26) across agents, we can express the relationship between relative income and relative wealth in terms of the corresponding standard deviations of their respective distributions, $\sigma_{q}(t), \sigma_{v}(t)$ by

$$
\sigma_{q}(t)=\varepsilon(t)\left[1-\left(\frac{\eta}{1+\eta}\right)\left(\frac{C(t)}{r(t) V(t)}\right)\left(\frac{\beta \widetilde{V}}{\widetilde{C}}\right) \frac{1}{\chi(t)}\right] \sigma_{v}(t)
$$

Hence the evolution of income inequality depends upon the time paths of two elements. The first is the dynamics of wealth inequality, $\sigma_{v}(t)$; the second is the dynamics of factor returns as they impact the share of income from net wealth, $\varepsilon(t)$, and the ratio of consumption to income from wealth. 
Assuming that the economy starts out in an initial steady state, (27) reduces to

$$
\widetilde{\sigma}_{q, 0}=\frac{1}{1+\eta}\left(\frac{\beta \widetilde{V}_{0}}{\beta \widetilde{V}_{0}+\widetilde{w}_{0} \widetilde{L}_{0}+\widetilde{T}_{0}}\right) \widetilde{\sigma}_{v, 0}=\left(\frac{\beta}{1+\eta}\right) \frac{\widetilde{V}_{0}}{\widetilde{C}_{0}} \widetilde{\sigma}_{v, 0}
$$

and dividing (27) by (28) we derive the following expression for income inequality relative to the initial long-run inequality

$$
\frac{\sigma_{q}(t)}{\widetilde{\sigma}_{q, 0}}=\varepsilon(t)\left[1-\left(\frac{\eta}{1+\eta}\right)\left(\frac{C(t)}{r(t) V(t)}\right)\left(\frac{\beta \widetilde{V}}{\widetilde{C}}\right) \frac{1}{\chi(t)}\right]\left(\frac{1+\eta}{\beta}\right) \frac{\widetilde{C}_{0}}{\widetilde{V}_{0}} \frac{\sigma_{v}(t)}{\widetilde{\sigma}_{v, 0}}
$$

In steady state (29) simplifies to:

$$
\frac{\widetilde{\sigma}_{q}}{\widetilde{\sigma}_{q, 0}}=\left(\frac{\widetilde{C}_{0} / \widetilde{V}_{0}}{\widetilde{C} / \widetilde{V}}\right) \frac{\widetilde{\sigma}_{v}}{\widetilde{\sigma}_{v, 0}}
$$

so that long-run income inequality varies positively with long-run changes in wealth inequality and inversely with changes in the gross consumption-wealth ratio. Recalling (15) we may state

Proposition 2: By reducing the gross consumption-wealth ratio a tariff reduction will increase long-run income inequality. To the extent that it decreases (increases) wealth inequality it will decrease (further increase) income inequality.

Thus, the overall effect will need to take account of both these effects. As our numerical simulations suggest, although wealth inequality is likely to decline, this effect is dominated by the response of the consumption-wealth ratio, so that long-run income inequality rises.

\section{Numerical Analysis}

Being a relatively high order system, to study the local dynamics of the economy in response to a reduction in tariffs, we return to the linearized system (A.2), which we solve numerically. The simulations are based on the constant elasticity utility function, (3a), together with the Cobb-Douglas production function, $F(K, L)=A K^{\alpha} L^{1-\alpha}$, and the constant elasticity export function, $Z(s)=b s^{c}$. In addition, we assume the borrowing and lending constraints

$$
\begin{aligned}
i\left(\frac{s D}{K}\right) & =i^{*}+\zeta\left[e^{a(s D / K)}-1\right] \\
i\left(\frac{s B}{K}\right) & =i^{*}-\zeta\left[e^{a(s B / K)}-1\right]
\end{aligned}
$$

which have the properties as specified by (4). 


\subsection{Calibration}

The parameters used to calibrate the benchmark economy are summarized in Table 1, which represents a typical emerging or developed open economy. We consider two different scenarios: Case I where $\left(i^{*}>\beta\right)$ and the country is a lender, and Case II where $\left(i^{*}<\beta\right)$ and it is a debtor, with our choices of $\beta$ and $i^{*}$ yielding plausible examples of both cases This is of some significance since certain aspects of the dynamics and long-run adjustments are sensitive to the economy's net asset position. ${ }^{18}$ Setting $\gamma=-1.5$ implies an intertemporal elasticity of substitution equal to 0.4 , well within the range of empirical estimates, while the other preference parameter, $\eta$, is chosen to ensure a plausible equilibrium allocation of time to leisure of around 0.70 , is also consistent with the available evidence. ${ }^{19}$ The relative weights of domestic vs. imported consumption $\theta=0.5,0.75$ span the range of importsGDP ratios of most emerging and developed economies, while the export demand elasticity $b=3$ is consistent with empirical evidence. ${ }^{20}$ The borrowing premium $a=$ 0.15 and the weight on the borrowing premium $\xi$ are chosen in order to attain a plausible debt to output ratio for debtor countries, and likewise for creditor economies. The base tariff is set at $10 \%$, which is close to the average of low and middle income countries for around 1990; see World Bank (2014). In both cases it generates a tax revenue of around $3.9 \%$ of GDP, which is also consistent with the revenues generated by tariffs.

The resulting macroeconomic equilibrium is summarized in Table 2. Row 1 in the first panel of Part A reports the key steady-state equilibrium values for the case of the creditor economy, taking $\theta=0.75$ as the benchmark allocation of consumption goods. It implies an equilibrium capital-output ratio of 4 and a credit-output ratio of 0.53 . The corresponding row of Part B reports the equilibrium for a debtor nation. This yields a capital output ratio of around 3.27 and an equilibrium debt-output ratio of around 0.42 . As one would expect, with the two economies being otherwise structurally identical, the debtor economy has less output and capital than does a similar credit economy. Table 3 reports the initial measures of wealth and income inequality, as measured by their respective coefficient of variation, where the initial wealth inequality is normalized to one.

While we do not attempt to calibrate to a specific economy or episode, we view these as providing plausible benchmarks designed to facilitate our understanding of the mechanisms in play as the economy evolves over time in response to a tariff reduction, the specification of which is as follows. Starting from the initial benchmark, with the tariff rate at $10 \%$, we specify its elimination in two alternative ways. The first is immediate complete elimination. The second is where the elimination takes place gradually, at the known rate of $10 \%$ per year. In the latter case, the complete

\footnotetext{
18 In both cases we find that the equilibrium is a saddlepoint, implying that there is a unique stable adjustment path.

19 It implies an aggregate Frisch elasticity of around 1.2 well within the range adopted in macroeconomic simulations; see Keane and Rogerson (2012). The inconsistency between these aggregate values and the smaller estimates obtained from the micro data is an issue currently occupying the attention of labor economists. Keane and Rogerson (2012) offer a reconciliation that credibly supports the range typically adopted in macroeconomic simulations.

$20 \quad$ See World Bank (2014), Table 4.8
} 
Table 1 The Benchmark Economy

$\begin{array}{ll}\text { Preference parameters: } & \gamma=-1.5, \theta=0.75, \beta=0.04,0.06 \eta=1.75 \\ \text { Production parameters: } & \alpha=0.36 \\ \text { Productivity parameters: } & A=0.8 \\ \text { Depreciation rate: } & \delta=0.05 \\ \text { World interest rate: } & i^{*}=0.06,0.04 \\ \text { Premium on borrowing: } & a=0.15 \\ \text { Weight on the premium: } & \xi=1 \\ \text { Export function } & b=2.0, c=3.0 \\ \text { Tariffs: } & \tau=0.10\end{array}$

elimination of tariffs is achieved only asymptotically, although it is straightforward to impose a finite time horizon. The key point is that the moment the tariff is put in place, its future levels along the transitional path become fully anticipated and begin to influence behavior.

\section{Elimination of Tariffs}

We now consider the elimination of an initial $10 \%$ tariff, contrasting the dynamics in the cases of instantaneous versus gradual reduction.

\subsection{Instantaneous Elimination of Tariffs}

We shall focus first on the benchmark parameterization $\theta=0.75, a=0.15$ presented in the first panel of Table 2.A, corresponding to the creditor economy. As noted previously, the long-run effects on the aggregate economy are the same whether the tariff is eliminated instantly or gradually over time. The simulations suggest that reducing the tariff from $10 \%$ to zero will cause long-run output, employment, capital, and wealth to all increase by $1.61 \%$, while the international price of the imported good will increase by $3.28 \%$. Overall consumption expenditure (inclusive of tariffs) will decline, as will the domestic price of the imported good, and the consumption to wealth ratio. All of these results are consistent with (15).

Much the same responses are observed for a debtor country. The only significant difference is that whereas the increase in the international price stemming from the reduced tariffs causes a creditor country to reduce its lending, debtor countries borrow less. In both cases these responses stem directly from the nature of the borrowing/ lending function.

The dynamics are straightforward and are illustrated by the solid lines in Figs. 1 and 2. On impact, the immediate elimination of the tariffs raises the international price of imported goods, $s$, by around $2.3 \%$, leading to an immediate increase in exports (Fig. 1a and b). While the increase in $s$ is significant, it falls far short of the $10 \%$ reduction in tariffs and so the domestic price of the imported good declines, leading to an increase in imports (Fig. 1c). This dominates the export response and overall the balance of trade declines (consistent with the traditional Marshall-Lerner condition). At 
Table 2 Key steady-state equilibrium ratios and steady-state responses to tariff reduced from $10 \%$ to 0

\begin{tabular}{|c|c|c|c|c|c|c|c|c|c|}
\hline \multicolumn{10}{|c|}{ A. Creditor Country: $\beta=0.04, i^{*}=0.06$} \\
\hline & $\widetilde{Y}$ & $\widetilde{L}$ & $\widetilde{K}$ & $\widetilde{B}$ & $\widetilde{V}$ & $\widetilde{s}$ & $\widetilde{C}$ & $\tilde{x}$ & $\widetilde{y}$ \\
\hline \multicolumn{10}{|c|}{ Benchmark case: $a=0.15, \theta=0.75$} \\
\hline $\begin{array}{l}\text { Initial equilibrium } \\
\qquad(\tau=0.10)\end{array}$ & 0.467 & 0.303 & 1.867 & 0.723 & 2.114 & 0.341 & 0.392 & 0.294 & 0.261 \\
\hline $\begin{array}{l}\text { Eliminate tariff }(\tau=0) \\
\% \text { Change }\end{array}$ & $\begin{array}{l}0.472 \\
(+1.61)\end{array}$ & $\begin{array}{l}0.308 \\
(+1.61)\end{array}$ & $\begin{array}{l}1.897 \\
(+1.61)\end{array}$ & $\begin{array}{l}0.711 \\
(-1.62)\end{array}$ & $\begin{array}{l}2.147 \\
(+1.61)\end{array}$ & $\begin{array}{l}0.352 \\
(+3.28)\end{array}$ & $\begin{array}{l}0.389 \\
(-0.70)\end{array}$ & $\begin{array}{l}0.292 \\
(-0.70)\end{array}$ & $\begin{array}{l}0.276 \\
(+5.76)\end{array}$ \\
\hline \multicolumn{10}{|c|}{ More open in trade $a=0.15, \theta=0.50$} \\
\hline $\begin{array}{l}\text { Initial equilibrium } \\
\qquad(\tau=0.10)\end{array}$ & 0.459 & 0.298 & 1.836 & 0.552 & 2.079 & 0.440 & 0.395 & 0.197 & 0.408 \\
\hline $\begin{array}{l}\text { Eliminate tariff }(\tau=0) \\
\% \text { Change }\end{array}$ & $\begin{array}{l}0.474 \\
(+3.29)\end{array}$ & $\begin{array}{l}0.308 \\
(+3.29)\end{array}$ & $\begin{array}{l}1.897 \\
(+3.29)\end{array}$ & $\begin{array}{l}0554 \\
(+0.45)\end{array}$ & $\begin{array}{l}2.147 \\
(+3.29)\end{array}$ & $\begin{array}{l}0.452 \\
(+2.84)\end{array}$ & $\begin{array}{l}0.389 \\
(-1.40)\end{array}$ & $\begin{array}{l}0.195 \\
(-0.70)\end{array}$ & $\begin{array}{l}0.431 \\
(+5.47)\end{array}$ \\
\hline \multicolumn{10}{|c|}{ More open in finance $\mathrm{a}=0.03, \theta=0.75$} \\
\hline $\begin{array}{l}\text { Initial equilibrium } \\
\qquad(\tau=0.10)\end{array}$ & 0.436 & 0.283 & 1.742 & 4.051 & 2.892 & 0.284 & 0.404 & 0.303 & 0.323 \\
\hline $\begin{array}{l}\text { Eliminate tariff }(\tau=0) \\
\% \text { Change }\end{array}$ & $\begin{array}{l}0.443 \\
(+1.66)\end{array}$ & $\begin{array}{l}0.288 \\
(+1.66)\end{array}$ & $\begin{array}{l}1.771 \\
(+1.66)\end{array}$ & $\begin{array}{l}3.909 \\
(-3.52)\end{array}$ & $\begin{array}{l}2.943 \\
(+1.66)\end{array}$ & $\begin{array}{l}0.299 \\
(+5.67)\end{array}$ & $\begin{array}{l}0.401 \\
(-1.67)\end{array}$ & $\begin{array}{l}0.301 \\
(-0.67)\end{array}$ & $\begin{array}{l}0.335 \\
(+3.72)\end{array}$ \\
\hline \multicolumn{10}{|c|}{ B. Debtor Country: $\beta=0.06, i^{*}=0.04$} \\
\hline & $\widetilde{Y}$ & $\widetilde{L}$ & $\widetilde{K}$ & $\widetilde{D}$ & $\widetilde{V}$ & $\widetilde{s}$ & $\widetilde{C}$ & $\widetilde{x}$ & $\tilde{y}$ \\
\hline \multicolumn{10}{|c|}{ Benchmark case: $\mathrm{a}=0.15, \theta=0.75$} \\
\hline $\begin{array}{l}\text { Initial equilibrium } \\
\qquad(\tau=0.10)\end{array}$ & 0.421 & 0.306 & 1.377 & 0.511 & 1.195 & 0.356 & 0.349 & 0.262 & 0.223 \\
\hline $\begin{array}{l}\text { Eliminate tariff }(\tau=0) \\
\% \text { Change }\end{array}$ & $\begin{array}{l}0.428 \\
(+1.60)\end{array}$ & $\begin{array}{l}0.311 \\
(+1.60)\end{array}$ & $\begin{array}{l}1.399 \\
(+1.60)\end{array}$ & $\begin{array}{l}0.505 \\
(-1.06)\end{array}$ & $\begin{array}{l}1.214 \\
(+1.60)\end{array}$ & $\begin{array}{l}0.366 \\
(+2.69)\end{array}$ & $\begin{array}{l}0.346 \\
(-0.71)\end{array}$ & $\begin{array}{l}0.260 \\
(-0.71)\end{array}$ & $\begin{array}{l}0.237 \\
(+6.36)\end{array}$ \\
\hline \multicolumn{10}{|c|}{ More open in trade $\mathrm{a}=0.15, \theta=0.50$} \\
\hline $\begin{array}{l}\text { Initial equilibrium } \\
\qquad(\tau=0.10)\end{array}$ & 0.414 & 0.301 & 1.332 & 0.406 & 1.176 & 0.440 & 0.351 & 0.176 & 0.363 \\
\hline $\begin{array}{l}\text { Eliminate tariff }(\tau=0) \\
\% \text { Change }\end{array}$ & $\begin{array}{l}0.428 \\
(+3.28)\end{array}$ & $\begin{array}{l}0.311 \\
(+3.28)\end{array}$ & $\begin{array}{l}1.399 \\
(+3.28)\end{array}$ & $\begin{array}{l}0.409 \\
(+0.63)\end{array}$ & $\begin{array}{l}1.214 \\
+(3.28)\end{array}$ & $\begin{array}{l}0.452 \\
(+2.64)\end{array}$ & $\begin{array}{l}0.346 \\
(-1.41)\end{array}$ & $\begin{array}{l}0.173 \\
(-1.41)\end{array}$ & $\begin{array}{l}0.383 \\
(+5.66)\end{array}$ \\
\hline \multicolumn{10}{|c|}{ More open in finance $\mathrm{a}=0.03, \theta=0.75$} \\
\hline $\begin{array}{l}\text { Initial equilibrium } \\
\qquad(\tau=0.10)\end{array}$ & 0.462 & 0.336 & 1.511 & 2.445 & 0.514 & 0.408 & 0.334 & 0.250 & 0.186 \\
\hline Eliminate tariff $(\tau=0)$ & 0.469 & 0.341 & 1.534 & 2.437 & 0.522 & 0.416 & 0.331 & 0.243 & 0.199 \\
\hline$\%$ Change & $(+1.54)$ & $(+1.54)$ & $(+1.54)$ & $(-0.36)$ & $(+1.54)$ & $(+1.88)$ & $(-0.78)$ & $(-0.76)$ & $(+7.15)$ \\
\hline
\end{tabular}

the same time, the increase in $s$ increases the lending country's relative share in the world bond market constraining its interest rate, reducing the capital account and thus the overall current account, causing its overall holdings of foreign bonds to decline (Fig. 1d and e).

Domestically, the increase in exports stimulates production, and output increases by a little over $1 \%$ (Fig. 1f). With the capital stock fixed in the short run, this is met by an increase in labor supply which increases instantaneously from its initial equilibrium of 0.303 to in excess of its long-run response of 0.308 (Fig. 1g). The increase in labor supply leads to a sharp reduction in wages accompanied by an increase in the return to capital (Fig. 1h and i). The implied reduction in leisure reduces the marginal utility of domestic consumption so that $x$ immediately drops by about $1.4 \%$ (Fig. 1j). The increase in the return to capital stimulates investment so that the capital stock begins to 
Table 3 Key steady-state equilibrium ratios and steady-state responses to tariff reduced from $10 \%$ to 0

A. Creditor Country: $\beta=0.04, i^{*}=0.06$

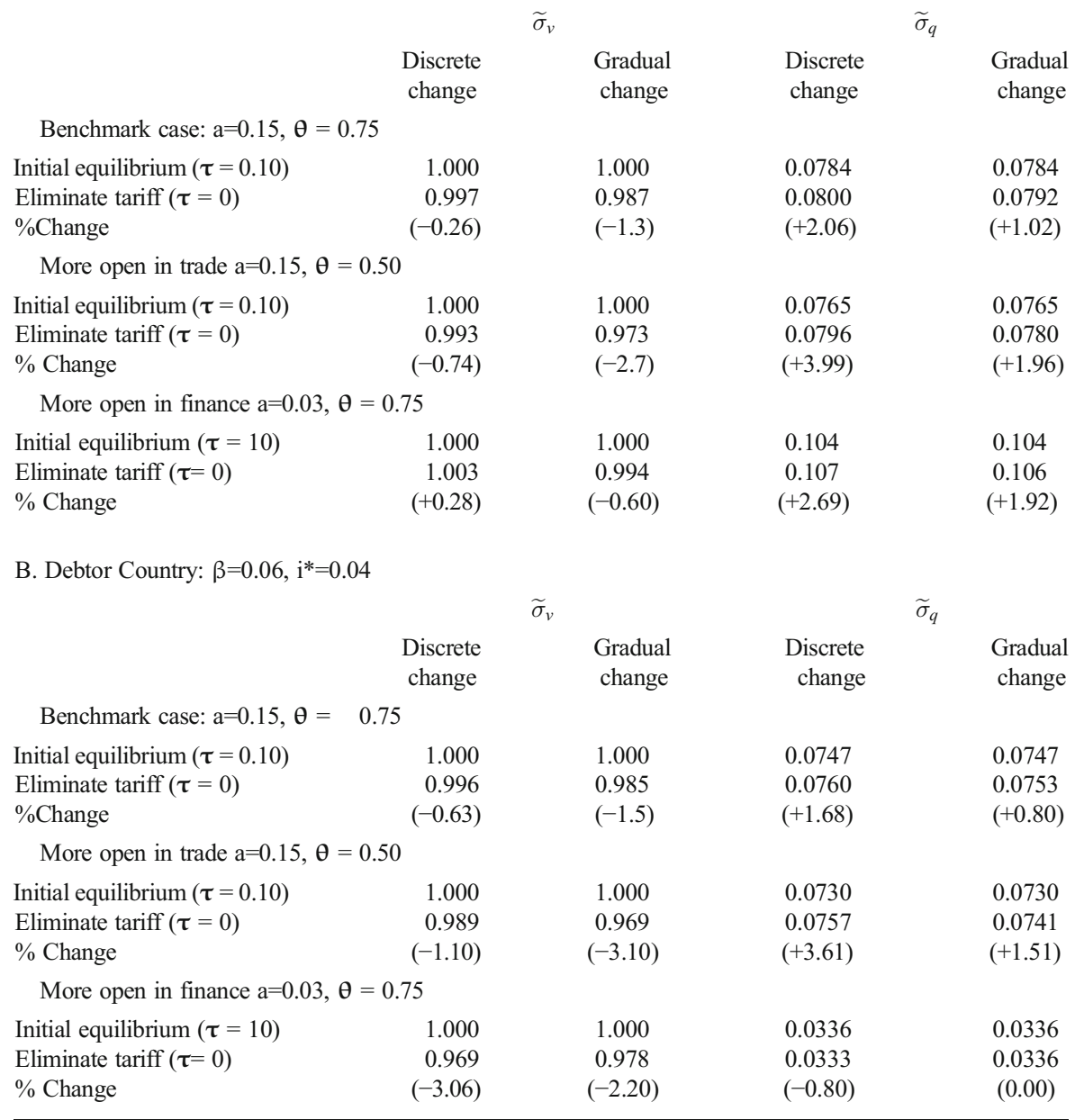

increase (Fig. 1k). Finally, while the reduction in tariffs reduces overall gross consumption expenditures, the increase in the relative price raises wealth (measured in terms of domestic output) and the consumption-wealth ratio rises (Fig. 11-n).

The transitional dynamics following these initial responses are driven by the subsequent evolution of capital and foreign bonds. As capital is accumulated, wages begin to rise and the return to capital declines (Fig. $1 \mathrm{~h}$ and i). This causes firms to substitute capital for labor in production, so that employment of labor gradually declines, albeit slightly (Fig. 1g), and output continues to expand (Fig. 1f). The increasing leisure raises the marginal utility of domestic consumption so that $x$ begins to increase (Fig. 1j). With the tariff now removed the increase in $x$ must be matched by the increase in sy in order for demand to be consistent with supply; see eqs. (11a, 11b). How this is allocated between the imported consumption good and its price depends upon the openness of 


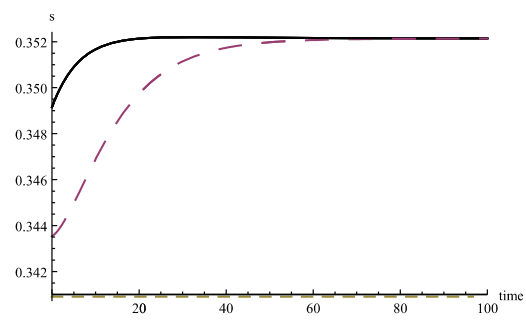

(a) Relative Price

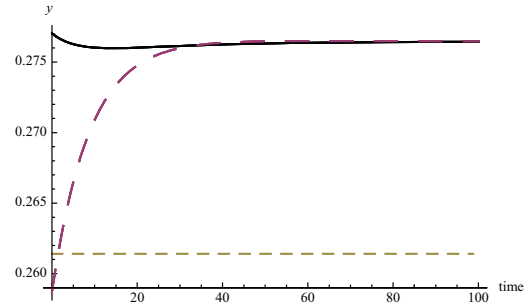

(c) Consumption Imported Good

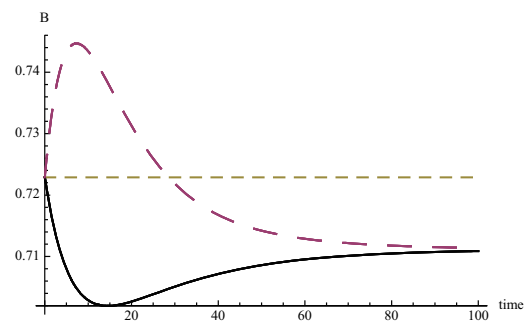

(e) Bonds

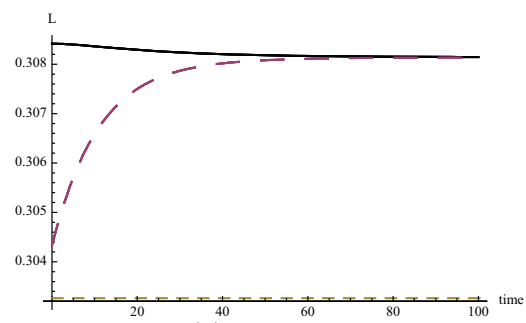

(g) Labor Supply

Initial equilibrium

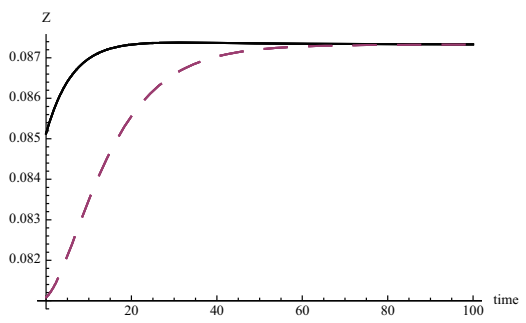

(b) Exports

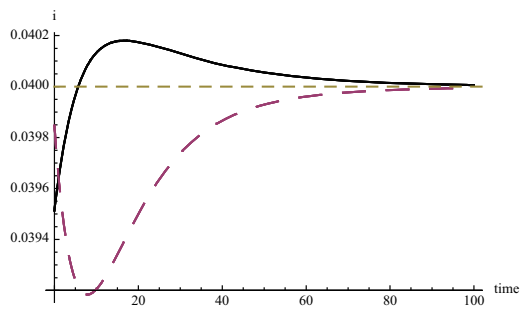

(d) Interest Rate

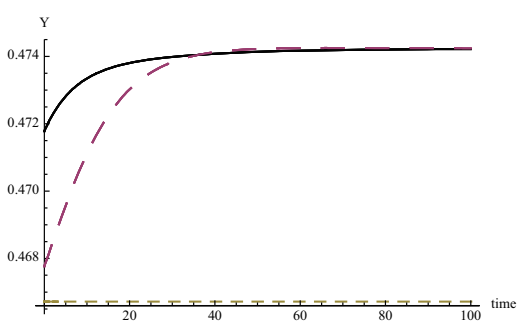

(f) Output

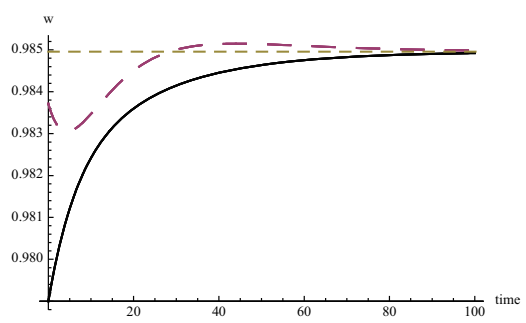

(h) Wages

Fig. 1 Creditor Nation $\left(i^{*}>\beta\right)$. Elimination of tariff from $10 \%$

the economy, $\theta$. For $\theta=0.75$, the initial jump in $s(0)$ is relatively small, $s$ increases at a faster rate than does $x$ and $y$ actually declines, but at a very slight rate.

As the capital stock increases, the initial decline in the interest rate is arrested and it gradually reverts to its original equilibrium rate $\beta=0.04$. As a result, the decline in the current account is reversed and after about 15 years it becomes positive and foreign bonds are accumulated, partially regaining their initial equilibrium levels. With the declining marginal productivity of capital, the rate of capital accumulation slows down and the aggregate economy converges to its new steady-state equilibrium. 


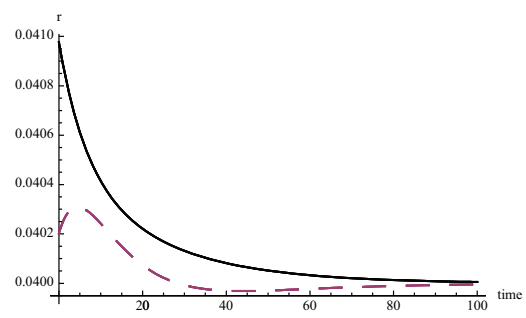

(i) Returnon Capital

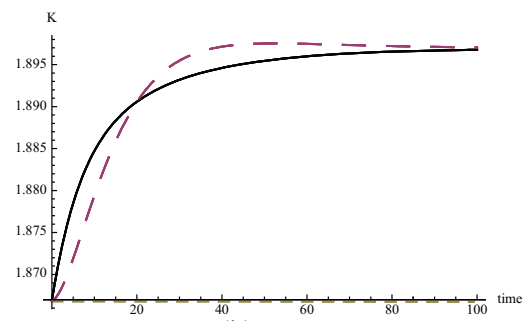

(k) Capital

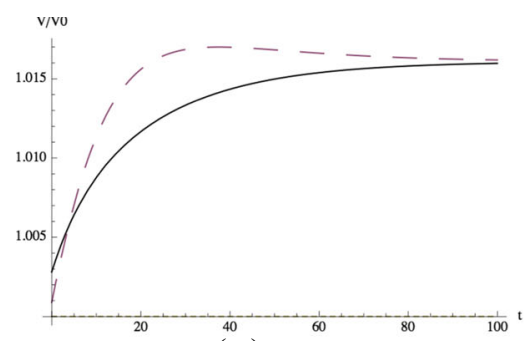

(m) Wealth

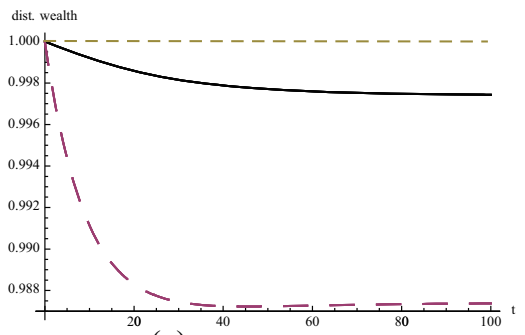

(o) Wealth Inequality

Initial equilibrium

— Instantaneous reduction

Fig. 1 (continued)

Turning now to the inequality measures, the aggregate evolution we have been describing are reflected in the dynamics of wealth inequality and income inequality, which as noted previously are dependent on the time path followed by the tariff reduction (Fig. 1o and p). With tariffs being removed immediately, (22) implies that the dynamics of wealth inequality is driven entirely by the time path of labor supply during the transition. And with the labor supply declining gradually during the transition (following its initial increase) (22) further implies that wealth inequality will decline gradually, albeit it slightly by $0.26 \%$. Income inequality, in contrast, responds 


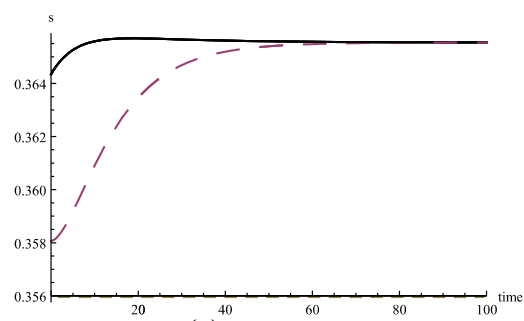

(a) Relative Price

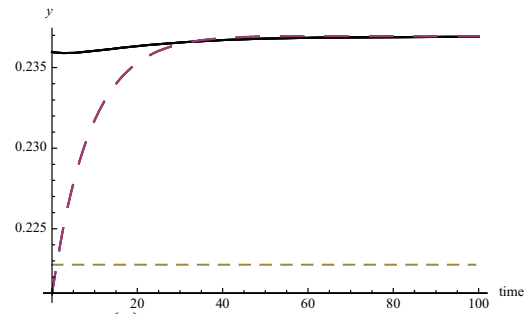

(c) Consumption Imported Good

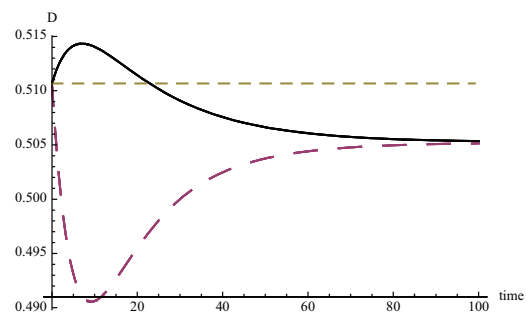

(e) Debt

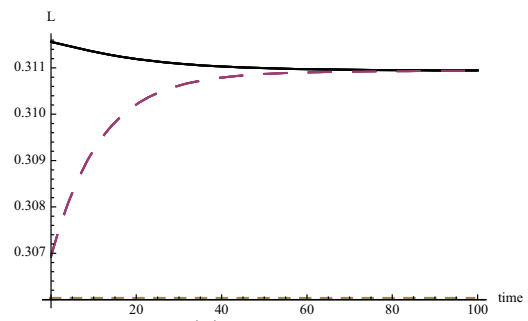

(g) Labor Supply

Initial equilibrium

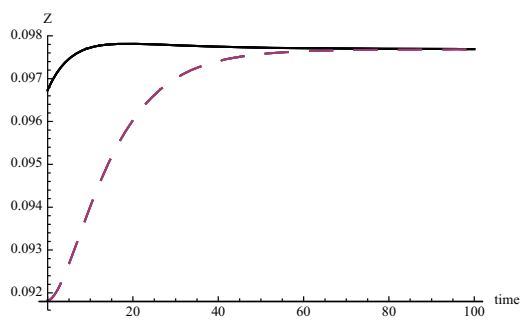

(b) Exports

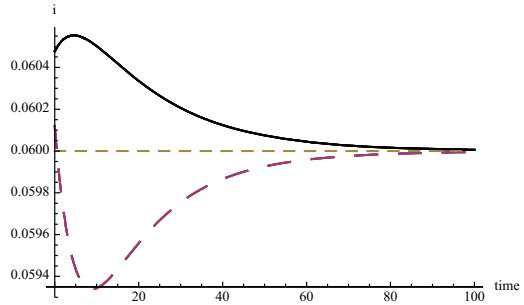

(d) Interest Rate

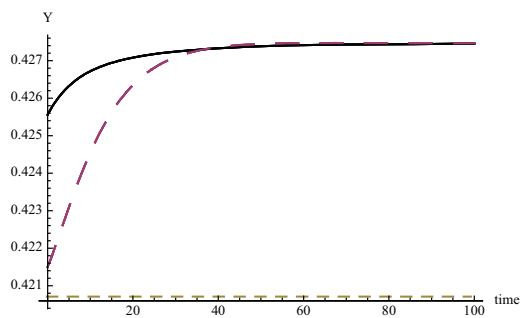

(f) Output

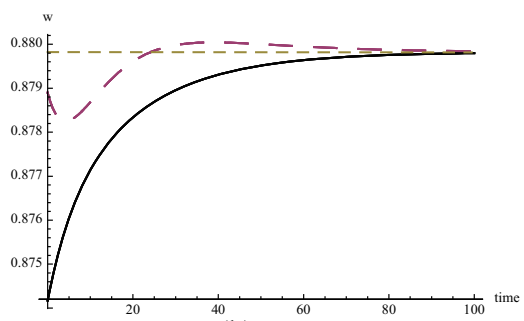

(h) Wages

Fig. 2 Debtor Nation $\left(\beta>i^{*}\right)$. Elimination of tariff from $10 \%$

non-monotonically. In the short-run the sharp increase in labor reduces the share of income due to capital and together with the decline in wealth inequality, income inequality declines by about $2 \%$. However, the rate of capital accumulation rapidly eradicates this and in the long run the decline in the consumption-wealth ratio declines sufficiently to suggest a long-run increase in income inequality of around $2 \%$.

The same patterns generally characterize the dynamic adjustments of a debtor economy, with some differences. First, the imperfection in the capital market is 


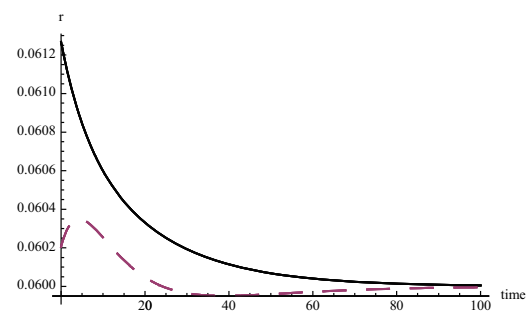

(i) Return on Capital

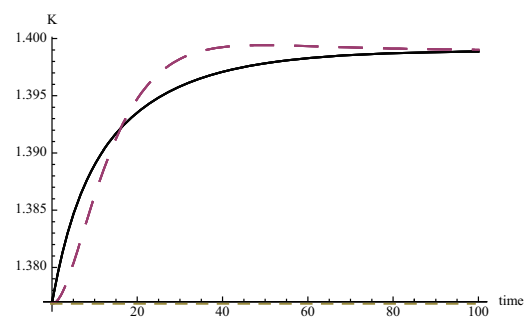

(k) Capital

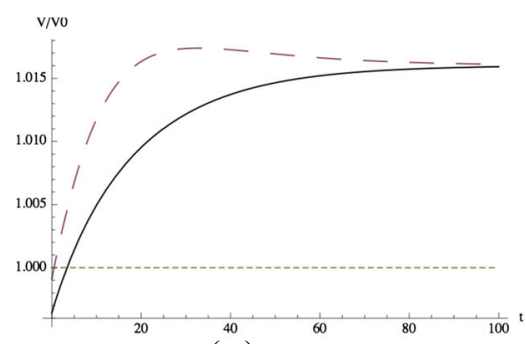

(m) Wealth

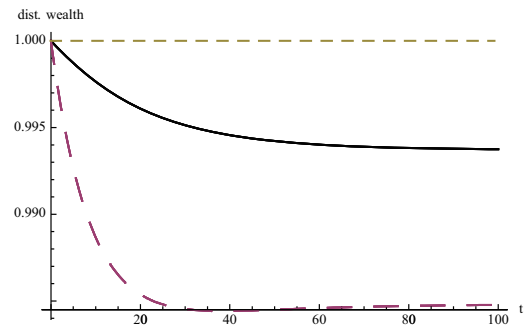

(o) Wealth Inequality

..... Initial equilibrium

Fig. 2 (continued)

reflected by a short-run increase in its borrowing rate, rather than a decline in its lending rate. Second, with the transitional decline in the labor supply more pronounced, the long-run decline in wealth inequality is around $0.63 \%$. Also, on impact income inequality increases by around $2 \%$ rather than declines, this being a reflection of the lower initial degree of income inequality in the debtor economy. Third, the "hump" characteristic of the transitional path of income inequality is more pronounced, so that in the long-run tariff reduction generates less income inequality than it does in the creditor economy.

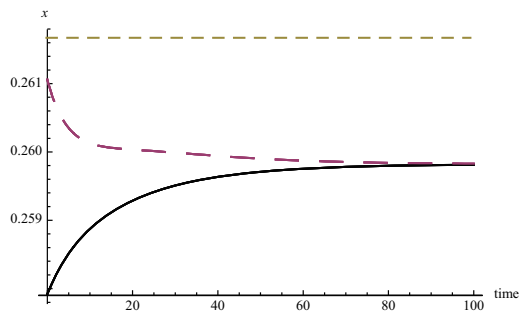

(j) Consumption Domestic Good

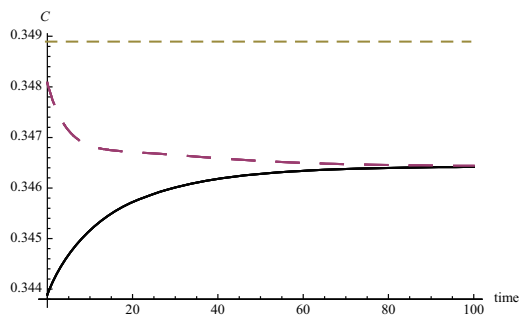

(1) Gross Consumption (including tariff payment)

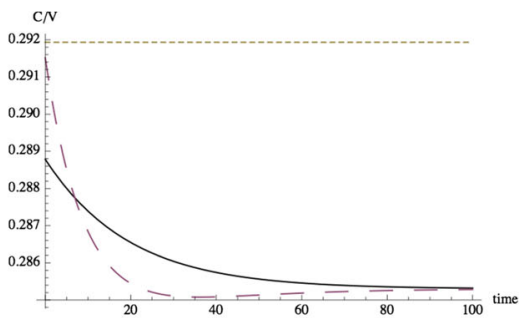

(n) Consumption-Wealth Ratio

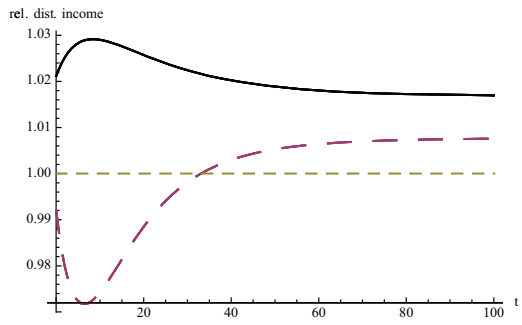

(p) Income Inequality

- - Gradual reduction
_ Instantaneous reduction 


\subsection{Gradual Elimination of Tariffs}

While the long-run responses of the aggregate variables are unaffected by the time path followed by the tariff reduction, the transitional paths, however, are quite different, leading to substantial differences in the distributions of wealth and income, both during the adjustment and in steady state. In some cases the short-run responses are in the oppose direction from those followed when the tariff elimination is completed instantaneously. The key to understanding the difference is the fact that in contrast to when the full change takes effect immediately at time $t=0$, tariffs at time $0, \tau(0)$ remain unchanged; instead, $\dot{\tau}(0)$ begins to decline and agents now fully anticipate the subsequent future reduction in the tariffs.

The dynamic time paths are now illustrated by the dashed lines in Fig. 1, and again we shall focus on the creditor nation. The anticipation of the eventual elimination of the tariff raises the international price of the imported good, $s$, though not by as much as when the tariff is eliminated immediately. The relative price now increases by only $0.7 \%$, leading to a much smaller increase in exports (Fig. 1a and b). With the tariff remaining unchanged, the domestic price of the imported good immediately increases, leading to an initial decline in imports (Fig. 1c) leading to an increase, rather than a decrease in the balance of trade. With the small change in the relative price, the impact on the interest rate is small and the country runs a current account surplus, increasing, rather than decreasing, its holdings of foreign bonds; (Fig. 1e).

The small increase in exports leads to a modest increase in domestic production, which is met by a small increase in labor supply by about 0.5 percentage points from its initial equilibrium of 0.303 to something over 0.304 (Fig. 1g). This in turn leads to a small reduction in the wage rate, a small increase in the return to capital (Fig. $1 \mathrm{~h}$ and i), a small decline in leisure leading to small decline in the consumption of the domestic good (Fig. 1j). Capital also begins to rise, but at a slower rate.

In the early stages of the transition, while tariffs are slow to decline, this pattern will generally continue. However, over time, as the tariff reduction continues, it begins to play a more dominant role and some of these trends begin to be reversed. Thus, for example, imports begin to increase and the rising international price, $s$, increases exports, stimulates the domestic economy, increasing output, employment, and capital accumulation. As a result of all these responses the decline in the real wage rate is reversed and the current account surplus is eventually reversed.

The increase in labor supply during the transition tends to increase wealth inequality. However, this is now accompanied by a declining tariff rate, which has precisely the opposite effect. Moreover, since the reduction in the tariff during the transition is 10 percentage points, while the increase in labor supply is of the order of $1 \%$, this effect dominates and wealth inequality declines by $1.3 \%$, substantially more than when the tariff is eliminated immediately.

The rapid decline in wealth inequality coupled with the initial decline in the income share of capital leads to a short-run decline in income inequality, which is eventually reversed over time. This is because, while the reduction in wealth inequality levels off, with the gradual tariff reduction, the impact of the reduction in the consumption-wealth ratio takes time to build up, but eventually dominates. However, the larger long-run decline in wealth inequality moderates the long-run increase in income inequality 
which is now reduced to $1.02 \%$, approximately half that when the tariff is eliminated instantaneously. $^{21}$

\subsection{Increase in Openness}

The second and third panels in Tables 2 and 3 vary the degree of openness of the economy, focusing in turn on the case where the economy is more open to trade $(\theta=$ $0.5)$ and where the economy is more open in the financial market $(a=0.03)$.

As $\theta$ declines from 0.75 to 0.50 and the economy becomes more open in trade the elimination of the tariffs has a more expansionary effect, and output and employment increase by $3.29 \%$. The qualitative responses remain largely as illustrated in Fig. 1, both for the creditor and debtor economies. The larger adjustment in labor supply along the transition means that wealth inequality declines more, but the larger reduction in the consumption to wealth ratio means a larger increase in income inequality.

As $a$ decreases from 0.15 to 0.03 and the economy becomes more open in the financial sector, more qualitative differences emerge. The lending economy lends more and has higher consumption of both domestic and imported goods. More of its consumption is financed by its wealth, and output and employment are lower than in the benchmark economy. In this case the immediate elimination of tariffs is associated with a transitional path of increasing labor supply, causing wealth inequality to increase over time and to contribute toward the overall increase in income inequality that occurs.

The responses of a debtor economy summarized in Panel B are generally similar, both qualitatively and quantitatively. The main difference arises in the case when borrowing costs decline, in which case the elimination of the tariff has less impact on its debt reduction. With immediate tariff elimination wealth inequality actually declines to a sufficient degree that it dominates the impact of the decline in the consumption-wealth ratio and overall income inequality is reduced. In short, whereas in most cases a tariff reduction leads to a decline in wealth inequality accompanied by an increase in income equality, if the economy has relatively free access to the world financial market, both wealth and income inequality increase for a creditor economy and both decline for a debtor.

\section{Conclusions}

It is widely accepted that the recent increase in trade liberalization has had substantial distributional consequences, although the direction of the relationship and the

\footnotetext{
21 The fact that our numerical analysis suggests that the removal of tariffs is generally associated with an increase in income inequality may appear to contradict the empirical evidence of Jaumotte et al. (2013) who find that over the period 1981-2003 a reduction in tariffs is associated with a reduction in income inequality. The difference can be reconciled by noting that their analysis uses a mix of inequality data based on income and consumption. From (19a) we see that long-run consumption inequality is proportional to wealth inequality, which we find decreases with the removal of tariffs, thus implying a much weaker overall relationship between tariffs and income inequality.
} 
mechanism driving it has been open to debate. In this paper we have analyzed the impact of tariff reductions on the dynamics of wealth and income inequality in a growing economy in which agents accumulate both physical capital and international bonds. Our study, which comprises a combination of formal analysis, supplemented with numerical simulations, suggests that in the long run the tariff reduction will be expansionary and be associated with both a reduction in wealth inequality but an increase in income inequality.

One of the key characteristics of our analysis is the importance of the speed with which any change in tariff policy is implemented. Thus we find that reducing tariffs gradually will likely lead to a decrease in income inequality during the transition and a substantially mitigated long-run increase. However, this will be associated with a slower increase in output, particularly in the early stages of the transition. This implies a short-run tradeoff between the increase in activity and inequality that a policymaker implementing a tariff reduction policy will need to take into account in determining how rapidly such a policy should be introduced. The fact that developing countries have typically liberalized tariffs at a faster rate than have developed countries may be a contributing factor to their higher degree of income inequality.

Acknowledgments Turnovsky's research was supported by the Van Voorhis endowment at the University of Washington. Comments received at the 2014 Conference of the Association of Public Economic Theory, the 2014 Annual Conference of the Chilean Economic Association, and the 4th International Economic Conference of the Turkish Economic Association are gratefully acknowledged.

\section{Appendix}

\section{Dynamics of Aggregate Economy}

Linearizing (13) around their steady state, (14), we may write the dynamics as

$$
\left(\begin{array}{c}
\dot{K}(t) \\
\dot{B}(t) \\
\dot{S}(t) \\
\dot{L}(t) \\
\dot{\tau}(t)
\end{array}\right)=\left(\begin{array}{ccccc}
a_{11} & a_{12} & a_{13} & a_{14} & 0 \\
a_{21} & a_{22} & a_{23} & a_{24} & a_{25} \\
a_{31} & a_{32} & a_{33} & a_{34} & 0 \\
a_{41} & a_{42} & a_{43} & a_{44} & a_{45} \\
0 & 0 & 0 & 0 & -\lambda
\end{array}\right)\left(\begin{array}{c}
K(t)-\widetilde{K} \\
B(t)-\widetilde{B} \\
s(t)-\widetilde{s} \\
L(t)-\widetilde{L} \\
\tau(t)-\widetilde{\tau}
\end{array}\right)
$$

where $a_{i j}$ is the corresponding partial derivative evaluated at steady state. Since these are easily computed, there is no need to report them. This is a fifth order system with three sluggish variables, $K(t), B(t)$, and $\tau(t)$ and two jump variables $s(t)$ and $L(t)$. It will have a unique stable adjustment path if and only if there are three stable eigenvalues: (i) $-\lambda$ and (ii) $\mu_{1}, \mu_{2}$, where $\mu_{1}<0, \mu_{2}<0$ are the two negative roots to the internal system specified by the sub-matrix $A=\left(a_{i j}\right), i=1, \ldots 4, j=1, \ldots 4$. In this case the system is a saddlepoint, with the stable solution being given by

$$
\begin{gathered}
K(t)-\widetilde{K}=A_{1} e^{\mu_{1} t}+A_{2} e^{\mu_{2} t}+\pi_{1}\left(\tau_{0}-\widetilde{\tau}\right) e^{-\lambda t} \\
B(t)-\widetilde{B}=A_{1} \kappa_{21} e^{\mu_{1} t}+A_{2} \kappa_{22} e^{\mu_{2} t}+\pi_{2}\left(\tau_{0}-\widetilde{\tau}\right) e^{-\lambda t}
\end{gathered}
$$




$$
\begin{aligned}
& s(t)-\widetilde{s}=A_{1} \kappa_{31} e^{\mu_{1} t}+A_{2} \kappa_{32} e^{\mu_{2} t}+\pi_{3}\left(\tau_{0}-\widetilde{\tau}\right) e^{-\lambda t} \\
& L(t)-\widetilde{L}=A_{1} \kappa_{41} e^{\mu_{1} t}+A_{2} \kappa_{42} e^{\mu_{2} t}+\pi_{4}\left(\tau_{0}-\widetilde{\tau}\right) e^{-\lambda t}
\end{aligned}
$$

where $\left(1, \kappa_{2 j}, \kappa_{3 j}, \kappa_{4 j}\right)^{\prime}$ for $j=1,2$ is the normalized eigenvector associated with the stable eigenvalue $\mu_{j}$ and $\pi_{i}, i=1, \ldots, 4$ are the solutions to:

$$
\left(\begin{array}{cccc}
a_{11}+\lambda & a_{12} & a_{13} & a_{14} \\
a_{21} & a_{22}+\lambda & a_{23} & a_{24} \\
a_{31} & a_{32} & a_{33}+\lambda & a_{34} \\
a_{41} & a_{42} & a_{43} & a_{44}+\lambda
\end{array}\right)\left(\begin{array}{c}
\pi_{1} \\
\pi_{2} \\
\pi_{3} \\
\pi_{4}
\end{array}\right)=\left(\begin{array}{c}
0 \\
-a_{25} \\
0 \\
-a_{45}
\end{array}\right)
$$

The arbitrary constants, $A_{1}, A_{2}$ are obtained from initial conditions on $K_{0}, B_{0}$ namely

$$
\begin{gathered}
A_{1}+A_{2}=\left(K_{0}-\widetilde{K}\right)-\pi_{1}\left(\tau_{0}-\widetilde{\tau}\right) \\
A_{1} \kappa_{21}+A_{2} \kappa_{22}=\left(B_{0}-\widetilde{B}\right)-\pi_{2}\left(\tau_{0}-\widetilde{\tau}\right)
\end{gathered}
$$

The system of equations (A.2)-(A.4) provides the basis for the analysis of the transitional dynamics. With $A_{1}, A_{2}$ determined by (A.4a) and (A.4b), the initial values of $s(0)$, $L(0)$ are

$$
\begin{aligned}
& s(0)=\widetilde{s}+A_{1} \kappa_{31}+A_{2} \kappa_{32}+\pi_{3}\left(\tau_{0}-\widetilde{\tau}\right) \\
& L(0)=\widetilde{L}+A_{1} \kappa_{41}+A_{2} \kappa_{42}+\pi_{4}\left(\tau_{0}-\widetilde{\tau}\right)
\end{aligned}
$$

Having obtained $\pi_{1}, \ldots, \pi_{4}, A_{1}, A_{2}$ the transitional dynamics follow (A.2). The case that $\tau$ is adjusted fully at time 0 is obtained by letting $\lambda \rightarrow \infty$ in this case the corresponding solution is

$$
\begin{gathered}
K(t)-\widetilde{K}=A_{1}^{\prime} e^{\mu_{1} t}+A_{2}^{\prime} e^{\mu_{2} t} \\
B(t)-\widetilde{B}=A_{1}^{\prime} \kappa_{21} e^{\mu_{1} t}+A_{2}^{\prime} \kappa_{22} e^{\mu_{2} t} \\
s(t)-\widetilde{S}=A_{1}^{\prime} \kappa_{31} e^{\mu_{1} t}+A_{2}^{\prime} \kappa_{32} e^{\mu_{2} t} \\
L(t)-\widetilde{L}=A_{1}^{\prime} \kappa_{41} e^{\mu_{1} t}+A_{2}^{\prime} \kappa_{42} e^{\mu_{2} t}
\end{gathered}
$$

where

$$
\begin{gathered}
A_{1}^{\prime}+A_{2}^{\prime}=\left(K_{0}-\widetilde{K}\right) \\
A_{1}^{\prime} \kappa_{21}+A_{2}^{\prime} \kappa_{22}=\left(B_{0}-\widetilde{B}\right)
\end{gathered}
$$




\section{Derivation of Equation (20)}

From equation (17), we have

$$
\dot{v}_{i}=\frac{1}{V}\left\{[C-T-w(K, L) L]\left(v_{i}-1\right)+(1+\eta)\left(1-\varphi_{i}\right) C\right\}
$$

where $T=\frac{\tau(1-\theta)}{1+\tau} C$ so that $C-T=\left(\frac{1+\tau \theta}{1+\tau}\right) C$. Substituting these expressions into (17):

$$
\dot{v}_{i}=\frac{1}{V}\left\{\left[\left(\frac{1+\tau \theta}{1+\tau}\right) C-w(K, L) L\right]\left(v_{i}-1\right)+(1+\eta)\left(1-\varphi_{i}\right) C\right\}
$$

Linearizing this expression around $\widetilde{v}_{i}, \widetilde{C}, \widetilde{K}, \widetilde{L}, \widetilde{\tau}$ yields the approximation

$$
\begin{aligned}
\dot{v}_{i}= & \frac{1}{\widetilde{V}}\left[\left(\frac{1+\tau \theta}{1+\tau}\right) \widetilde{C}-w(\widetilde{K}, \widetilde{L}) \widetilde{L}\right]\left(v_{i}-\widetilde{v}_{i}\right)+\frac{1}{\widetilde{V}}(1+\eta)\left(1-\varphi_{i}\right)(C-\widetilde{C}) \\
& +\frac{\left(\widetilde{v}_{i}-1\right)}{\widetilde{V}}\left[\left(\frac{1+\tau \theta}{1+\tau}\right)(C-\widetilde{C})-\widetilde{w}_{K} \widetilde{L}(K-\widetilde{K})-\left(\widetilde{w}_{L} \widetilde{L}+\widetilde{w}\right)(L-\widetilde{L})-\widetilde{C} \frac{(1-\theta)}{(1+\widetilde{\tau})^{2}}(\tau-\widetilde{\tau})\right]
\end{aligned}
$$

From the steady-state to (17) we obtain

$$
(1+\eta)\left(1-\varphi_{i}\right)=-\frac{(\widetilde{C}-\widetilde{T}-w(\widetilde{K}, \widetilde{L}) \widetilde{L})}{\widetilde{C}}\left(\widetilde{v}_{i}-1\right)=-\beta\left(\frac{\widetilde{V}}{\widetilde{C}}\right)\left(\widetilde{v}_{i}-1\right)
$$

Using this relationship in (A.6) yields

$$
\begin{aligned}
\dot{v}_{i}=\beta\left(v_{i}-\widetilde{v}_{i}\right)+\left(\widetilde{v}_{i}-1\right)\left(\frac{\widetilde{C}}{\widetilde{V}}\left(\frac{1+\tau \theta}{1+\tau}\right)-\beta\right)\left(\frac{C-\widetilde{C}}{\widetilde{C}}\right) \\
-\frac{\left(\widetilde{v}_{i}-1\right)}{\widetilde{V}}\left[\widetilde{w}_{K} \widetilde{L}(K-\widetilde{K})+\left(\widetilde{w}_{L} \widetilde{L}+\widetilde{w}\right)(L-\widetilde{L})+\widetilde{C} \frac{(1-\theta)}{(1+\widetilde{\tau})^{2}}(\tau-\widetilde{\tau})\right]
\end{aligned}
$$

Using the steady-state equilibrium condition, $\widetilde{C}=\beta \widetilde{V}+\widetilde{T}+\widetilde{w} \widetilde{L}$, we may rewrite (A.8) in the form

$$
\dot{v}_{i}=\beta\left(v_{i}-\widetilde{v}_{i}\right)+\frac{\left(\widetilde{v}_{i}-1\right)}{\widetilde{V}}\left[\widetilde{w} \widetilde{L}\left(\frac{C-\widetilde{C}}{\widetilde{C}}\right)-\widetilde{w}_{K} \widetilde{L}(K-\widetilde{K})-\left(\widetilde{w}_{L} \widetilde{L}+\widetilde{w}\right)(L-\widetilde{L})-\widetilde{C} \frac{(1-\theta)}{(1+\widetilde{\tau})^{2}}(\tau-\widetilde{\tau})\right]
$$

From $C=\frac{1}{\eta} w(K, L)(1-L)$ we obtain

$$
\frac{C-\widetilde{C}}{\widetilde{C}}=\frac{\widetilde{w}_{K}}{\widetilde{w}}(K-\widetilde{K})+\left(\frac{\widetilde{w}_{L}}{\widetilde{w}}-\frac{1}{1-\widetilde{L}}\right)(L-\widetilde{L})
$$

and substituting into (A.9) yields (20)

$$
\dot{v}_{i}(t)=\beta\left(v_{i}(t)-\widetilde{v}_{i}\right)-\frac{\left(\widetilde{v}_{i}-1\right)}{\widetilde{V}}\left[\frac{\widetilde{F}_{L}}{(1-\widetilde{L})}(L(t)-\widetilde{L})+\widetilde{C} \frac{(1-\theta)}{(1+\tau)^{2}}(\tau-\widetilde{\tau})\right]
$$




\section{References}

Atolia M, Chatterjee S, Turnovsky SJ (2012) Growth and inequality: dependence on the time path of productivity increases (and other structural changes). J Econ Dyn Control 36:331-348

Bergh A, Nilsson T (2010) Do liberalization and globalization increase income inequality? Eur J Polit Econ 26:488-505

Beyer H, Rojas P, Vergara R (1999) Trade liberalization and wage inequality. J Dev Econ 59:103-123

Bourguignon F, Morrison C (1990) Income distribution, development, and foreign trade: a cross-sectional analysis. Eur Econ Rev 34:1113-1132

Boyer R (1977) Commercial policy under alternative exchange rate regimes. Can J Econ 19:218-232

Caselli F, Ventura J (2000) A representative consumer theory of distribution. Am Econ Rev 90:909-926

Chan KS (1978) The employment effects of tariffs under a free exchange rate regime. J Int Econ 8:414 424

Deininger K, Squire L (1997) Economic growth and income inequality: reexamining the links. Financ Dev 34 : $38-41$

Dreher A, Gaston N (2008) Has globalization increased inequality? Rev Int Econ 16:516-536

Edwards S (1997) Trade policy, growth, and income distribution. Am Econ Rev 87:205-210

Eichengreen BJ (1981) A dynamic model of tariffs, output, and employment under flexible exchange rate. J Int Econ 11:341-359

Engel CM, Kletzer K (1990) Tariffs and savings in a model with new generations. J Int Econ 29:71-91

Fender J, Yip C (2000) Tariffs and exchange rate dynamics redux. J Int Money Financ 19:633-655

Forbes KJ (2000) A reassessment of the relationship between inequality and growth. Am Econ Rev 90:869887

Gardner G, Kimbrough K (1989) Tariffs, interest rates and the trade balance in the world economy. J Int Econ 27:91-110

Gavin M (1991) Tariffs and the current account. J Econ Dyn Control 15:27-52

Goldberg PK, Pavcnik N (2007) Distributional effects of globalization in developing countries. J Econ Lit 45: 39-82

Gorman W (1953) Community preference fields. Econometrica 21:63-80

Harrison A, Hanson G (1999) Who gains from trade reform? Some remaining puzzles. J Dev Econ 59:125154

Hwang Y-N, Turnovsky SJ (2013) Exchange rate pass-through and the effects of tariffs on economic performance and welfare. J Int Money Financ 33:81-102

Jaumotte F, Lall S, Papageorgiou C (2013) Rising income inequality: technology or trade and financial globalization? IMF Econ Rev 61:271-309

Keane M, Rogerson R (2012) Micro and macro labor supply elasticities: a reassessment of conventional wisdom. J Econ Lit 50:464-476

Kimbrough KP (1982) Real disturbances, the current account, and the exchange rate: the case of the tariff. J Int Econ 13:231-256

Krugman P (1982) The macroeconomics of protection with a floating exchange rate. Carn-Roch Conf Ser Public Policy 16:141-182

Kuznets S (1955) Economic growth and income inequality. Am Econ Rev 45:1-28

Lim G C, McNelis P D (2014) Income Inequality, Trade and Financial Openness. Melbourne Institute, Working Paper No. 7/14, Fordham University Schools of Business, Research Paper No. 2425068

Milanovic B, Squire L (2005) Does tariff liberalization increase wage inequality? Some empirical evidence. National Bureau of Economic Research, Working Paper No. 11046

Mundell R (1961) Flexible exchange rates and employment policy. Can J Econ Polit Sci 27:509-517

Obstfeld M, Rogoff K (1995) Exchange rate dynamics redux. J Polit Econ 103:624-660

Obstfeld M, Rogoff K (2000) New directions for stochastic open economy models. J Int Econ 50:117-153

Ostry J (1991) Tariffs, real exchange rates and the trade balance in a two-country world. Eur Econ Rev 35: $1127-1142$

Ostry J, Rose AK (1992) An empirical evaluation of the macroeconomic effects of tariffs. J Int Money Financ 11:63-79

Piketty T (2011) On the long-run evolution of inheritance: France 1820-2050. Q J Econ 61:1071-1131

Savvides A (1998) Trade policy and income inequality: new evidence. Econ Lett 61:365-372

Sen P, Turnovsky SJ (1989) Tariffs, capital accumulation, and the current account in a small open economy. Int Econ Rev 30:811-831

Sorger G (2000) Income and wealth distribution in a simple growth model. Econ Theory 16:23-42 
Stewart F, Berry A (2000) Globalization, liberalization, and inequality: real causes: expectations and experience. Challenge 43:44-92

Turnovsky SJ (1991) Tariffs and sectoral adjustments in an open economy. J Econ Dyn Control 15:53-89

Turnovsky SJ, García-Peñalosa C (2008) Distributional dynamics in a neoclassical growth model: the role of elastic labor supply. J Econ Dyn Control 32:1399-1431

World Bank (2014). World Development Indicators Database

Yip CK (1995) The macroeconomic dynamics of tariffs: a symmetric two country analysis. South Econ J 61: 1006-1019 